\title{
Effect of natural fractures on determining closure pressure
}

\author{
S. Nadimi ${ }^{1,2} \cdot$ B. Forbes $^{1} \cdot$ J. Moore ${ }^{1} \cdot$ J. D. McLennan ${ }^{1,2}$
}

Received: 29 July 2019 / Accepted: 23 August 2019 / Published online: 28 August 2019

(C) The Author(s) 2019

\begin{abstract}
In Utah FORGE reservoir, eight pressure transient tests (microhydraulic fracturing and DFIT ${ }^{\mathrm{TM}}$ ) show natural fracture/ pressure-dependent leakoff. This behavior may lead to misinterpretation of the closure pressure (proxy for minimum principal stress). The closure pressures obtained from DFIT ${ }^{\mathrm{TM}}$ (or microhydraulic fracturing) testing may reflect shear failure along natural fractures or discontinuities rather than tensile failure and lead to inaccurate estimates of the minimum principal stress. In pressure tests conducted at the Utah FORGE site showed that reactivation or opening of natural fractures intersecting the wellbore and were suggested by multiple closure events in DFITTM tests. In addition, comparisons between the pre- and postwell-tests FMI logs show that there are populations of induced fracture and reactivated natural fractures which are mostly vertical and sub-vertical. In this study, DFIT ${ }^{\mathrm{TM}}$ (or microhydraulic fracturing) test analysis and numerical simulations were used to suggest that hydraulic shearing of critically stressed natural fractures can contribute to multiple closure signatures and possibly lead to incorrect determination of the minimum principal stress. As other authors have previously advocated, the DFIT ${ }^{\mathrm{TM}}$ test analyses and numerical simulations suggest that better estimations of minimum principal stress may be derived by injecting at relatively high rate and pressure and insuring that tensile breakdown is reached. In addition, extended shut-in period is required to determine accurate reservoir characteristics and fluid flow regime.
\end{abstract}

Keywords Utah FORGE $\cdot$ Microhydraulic fracturing and DFIT ${ }^{\mathrm{TM}} \cdot$ Natural fracture/pressure-dependent leakoff $\cdot$ Minimum principal stress $\cdot$ Closure pressure $\cdot \mathrm{XSite}^{\mathrm{TM}}$

\section{List of symbols}

$\tau_{\mathrm{f}}$

$\eta$

$\sigma_{\mathrm{n}}$

$P_{\mathrm{C}}$

$\tau$

$l, m$, and $n$

$\sigma_{1}, \sigma_{2}$ and $\sigma_{3}$

$q$

$P_{\text {wf }}$

S. Nadimi

nadimisiavash@gmail.com

1 Energy and Geoscience Institute, University of Utah, Salt Lake City, UT 84108, USA

2 Department of Chemical Engineering, University of Utah, Salt Lake City, UT 84112, USA
$P_{i} \quad$ Reservoir pore pressure (psi)

II Injectivity index (bpm/psi)

\section{Introduction}

Various publications have studied injection-related fracturing mechanisms and characterized the Mode I, Mode II and mixed mode behavior caused by hydraulic injection (Nadimi 2015). Typical procedures for estimating the orientations of critically stressed fractures were presented by Ito and Hayashi (2003) and Nadimi et al. (2016). Morris et al. (1996) reaffirmed slippage tendencies, based on the ratio of the resolved shear stress to the resolved effective normal stress acting on a fracture plane. This concept was used to study the potential of fracture shearing and dilation in a deep geothermal reservoir in the Northeast German Basin. The probability of shearing along natural fractures was studied by Meller et al. (2012) using statistical analyses of the fracture distribution, length and orientation. This method was used to study shearing at the Soultz-sour-Forêts EGS project. Pine and Batchelor (1984) proposed shearing to explain 
the downward growth of microseismicity during hydraulic stimulation at the Rosemanowes EGS site during initiation and propagation.

Tensile initiation, reopening and fracture propagation during well testing and stimulation is usually considered as the primary mechanism hydraulic stimulation (Poe et al. $2000)$ in the oil and gas field. Initiation occurs when the fluid pressure exceeds the stress concentration and tensile strength at the borehole wall. Propagation overcomes the minimum principal stress, $\sigma_{3}$. Slip (shearing) is another possible stimulation mechanism in fractured reservoirs (Evans 2005; Zoback 2010). Initiation of natural fracture shearing can be mistaken for tensile fracturing and lead to an underestimation of the minimum principal stress. Studies have shown cases where the pressure during testing deviates from a linear trend early and causes a curved shape in a pressure versus volume plot (Couzens-Schultz and Chan 2010; Zoback and Healy 1992). Also, it was proposed that fluid loss along the conductive natural fractures causes abnormal leakoff behavior.

Well 58-32 was drilled at the Utah FORGE site to measure the thermal reservoir properties such as temperature, rock type, permeability and stress. Eight injection test cycles were conducted to determine the reservoir the permeability, closure pressure (minimum principal stress) and reservoir pressure. It is not clear to what extent significant fracture slip was initiated during DFITTM tests in well 58-32. Formation MicroImager logs (FMI) and pressure tests were used to investigate the effect of natural fractures which have on determining the closure pressure in naturally fractured, impermeable FORGE reservoir. In addition, numerical simulations were used to assess if hydraulic shearing of critically stressed natural fractures could cause multi-closure and lead to difficulties in determining the minimum principal stress.

\section{FORGE}

The Utah FORGE (Frontier Observatory for Research in Geothermal Energy) site has been chosen by the Department of Energy (DOE) as a location for testing and demonstrating new technologies that advance geothermal heat extraction from naturally fractured low-permeability host rocks. The primary purpose of this field laboratory is to demonstrate the viability of enhanced geothermal systems (EGS) energy development. The FORGE site is located $350 \mathrm{~km}$ south of Salt Lake City and $16 \mathrm{~km}$ north-northeast of Milford, Utah, between the basin and range (BR) and Colorado Plateau (CP) (Nadimi et al. 2018).

On September 23, 2017, as part of the injection measurement program, a falloff test, three microhydraulic fracturing tests and a Diagnostic Fracture Injection Test (DFIT ${ }^{\mathrm{TM}}$ ) with an extended shut-in period were run. Transmissibility was estimated using accepted after-closure analysis techniques (Poe et al. 2000). On the following day, a microhydraulic fracturing test, a step rate test (SRT) with an extended shutin and a Diagnostic Fracture Injection Test (DFIT ${ }^{\mathrm{TM}}$ ) were run. In this final DFIT ${ }^{\mathrm{TM}}$ cycle, a slug of viscosified fluid with proppant (200 mesh $\mathrm{CaCO}_{3}$ ) was pumped to enhance prominent fractures taking fluid-for subsequent FMI evaluation. After-closure analysis was also carried out after the step rate test. Table 1 shows the sequence of injection measurements taken on September 23 and September 24, 2017. Figure 1 shows the surface pressure data for the eight injection cycles.

\section{Fracture opening versus fracture slip in FORGE}

The Coulomb failure criterion has been adapted to estimate the shear strength of a single fracture in a reservoir (Xie and Min 2016),

$\tau_{\mathrm{f}}=\eta \sigma_{\mathrm{n}}$

where $\tau_{\mathrm{f}}$ is the shear strength of a fracture, $\sigma_{\mathrm{n}}$ is the normal stress on the fracture and $\eta$ is the frictional coefficient (the tangent of the friction angle $\varphi$ ). Cohesion of the fracture is neglected (Zoback et al. 2003).

During fluid injection, an elevated pressure inside a fracture leads to a decrease in the effective normal stress, resulting in a reduced frictional resistance to sliding. Fracture shearing initiates when the applied injection pressure is high enough to overcome the resistance to the applied (driving) shear stress, $\tau$, along the fracture surface. The magnitude of the critical pressure of a fracture is defined as:

$P_{\mathrm{C}}=\sigma_{\mathrm{n}}-\frac{\tau}{\eta}$

The resolved normal and shear stresses on the fracture surface can be calculated using the following equations:

$\sigma_{\mathrm{n}}=l^{2} \sigma_{1}+m^{2} \sigma_{2}+n^{2} \sigma_{3}$

$\tau=\left[\left(\sigma_{1}-\sigma_{2}\right)^{2} l^{2} m^{2}+\left(\sigma_{2}-\sigma_{3}\right)^{2} m^{2} n^{2}+\left(\sigma_{3}-\sigma_{1}\right)^{2} l^{2} n^{2}\right]$

where $l, m$ and $n$ are the direction cosines of the fracture plane normal with respect to the principal stress axes, $\sigma_{1}, \sigma_{2}$ and $\sigma_{3}$, respectively (Zoback and Healy 1992). The critical shearing pressure on a specific fracture can be calculated by substituting Eqs. (3) and (4) in Eq. (2). The critical shearing pressure varies with the fracture surface characteristics, orientation and stress conditions. It is well established that a fracture with its normal vector perpendicular to $\sigma_{2}$ and an angle of $\pi / 4+\varphi / 2$ to $\sigma_{3}$ is the most vulnerable fracture to shear. 
Table 1 Summary of stress and permeability measurements

\begin{tabular}{|c|c|c|}
\hline Cycle & Description & Purpose \\
\hline 1 & $\begin{array}{l}\text { Injection falloff: Pressure was increased to below the pressure } \\
\text { required to hydraulically fracture the formation. Well shut-in and } \\
\text { pressure decay monitored }\end{array}$ & $\begin{array}{l}\text { Assessment of native permeability before hydraulic fracturing } \\
\text { testing }\end{array}$ \\
\hline 2 & Microhydraulic fracture: $2.8 \mathrm{bbl}$ was pumped at $0.4 \mathrm{bpm}$ & Stress measurement \\
\hline 3 & Microhydraulic fracture: $4.2 \mathrm{bbl}$ was pumped at $0.4 \mathrm{bpm}$ & Stress measurement \\
\hline 4 & Microhydraulic fracture: $10.0 \mathrm{bbl}$ was pumped at $0.8 \mathrm{bpm}$ & Stress and permeability measurements \\
\hline 5 & $\begin{array}{l}\text { DFIT pumped initially at } 5.8 \mathrm{bpm} \text { and increased to } 8.7 \mathrm{bpm} \text { for } \\
5 \mathrm{~min} \text { ( } 67.2 \text { barrels pumped). Prolonged shut-in }\end{array}$ & Stress and permeability measurements \\
\hline 6 & Repeat microhydraulic fracture test. $0.4 \mathrm{bpm}$ and $3.8 \mathrm{bbl}$ pumped & Stress measurement \\
\hline 7 & $\begin{array}{l}76.9 \mathrm{bbl} \text { was pumped in a step rate test (SRT) where rate progres- } \\
\text { sively increased } \\
0.4 \mathrm{bpm}, 2.7 \mathrm{bbl} \text { pumped } \\
0.8 \mathrm{bpm}, 4.1 \mathrm{bbl} \text { pumped } \\
1.6 \mathrm{bpm}, 9.8 \mathrm{bbl} \text { pumped } \\
3.2 \mathrm{bpm}, 16.1 \mathrm{bbl} \text { pumped } \\
6.3 \mathrm{bpm}, 44.2 \mathrm{bbl} \text { pumped }\end{array}$ & $\begin{array}{l}\text { SRT is alternative method for evaluating minimum in situ stress as } \\
\text { a function of injection rate. Furthermore, shut-in pressure decline } \\
\text { at the end of the SRT can be used to pick fracture closure with } \\
\text { classic techniques. Permeability was also measured }\end{array}$ \\
\hline 8 & $\begin{array}{l}\text { Another DFIT. This injection sequence also contained an } 8 \mathrm{bbl} \\
\text { slug of viscosified fluid carrying } 200 \text {-mesh calcium carbonate } \\
\text { proppant. } 28.8 \mathrm{bbl} \text { of water at } 6.4 \mathrm{bpm} \text {, followed by } 8 \mathrm{bbl} \text { of } \\
\text { viscosified xanthan with } \mathrm{CaCO}_{3} \text { at } 6.4 \mathrm{bpm} \text {, displaced with } 3 \mathrm{bbl} \\
\text { of water at } 6.4 \mathrm{bpm} \text {, and } 8 \text { bbl of water at } 3 \mathrm{bpm} \text { to encourage } \\
\text { screenout and fracture packing for subsequent logging }\end{array}$ & Stress and permeability measurements \\
\hline
\end{tabular}


Fig. 1 Surface pressure during the injection campaign. The upper panel shows the injection program on September 22, and the lower panel shows the injection program for September 23
Figure 2 shows a critical pressure analysis and shearing reactivation in well 52-38. In the immediate vicinity of well $58-32$, the NE-SW fracture set contains the most optimally oriented discontinuities for shearing. The magnitude of the critical pressure was computed using Eq. (2) and is shown in Fig. 2 (solid line). The injection profile shifts toward right as surface pressure is applied during injection. The example shows a bottomhole pressure of approximately 900-1200 psi (depends on the friction angle) above the static hydrostatic pressure. The shearing may activate with an upward propagation if the injection pressure profile first meets the critical pressure profile at the top of the openhole section (casing shoe). Upward propagation only occurs due to the injection pressure exceeding the critical pressure. In this case, the gradient of the critical pressure is higher than the injection pressure gradient.

In the openhole section of the wellbore pressure (lowest $147 \mathrm{ft}$ ), the shearing may lead to propagation when the injection pressure profile first exceeds the critical pressure for shearing. The confounding aspect is that there were numerous drilling-induced tensile fractures in this well, even though there were no significant pressure excursions during drilling and the mud weight was only marginally above hydrostatic (500 psi maximum). The implication is that tensile fracturing could have occurred because of thermal stress reduction due to wellbore cooling, for example. Regardless, the tensile fractures are present.

Based on the study conducted by Brown and Hoek (1978) on the relationship between the measured in situ

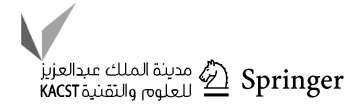


Fig. 2 Calculated critical pressure (shearing) and potential shearing initiation location of the openhole section of the Utah FORGE reservoir
FORGE-Upward shearing starts at casing shoe

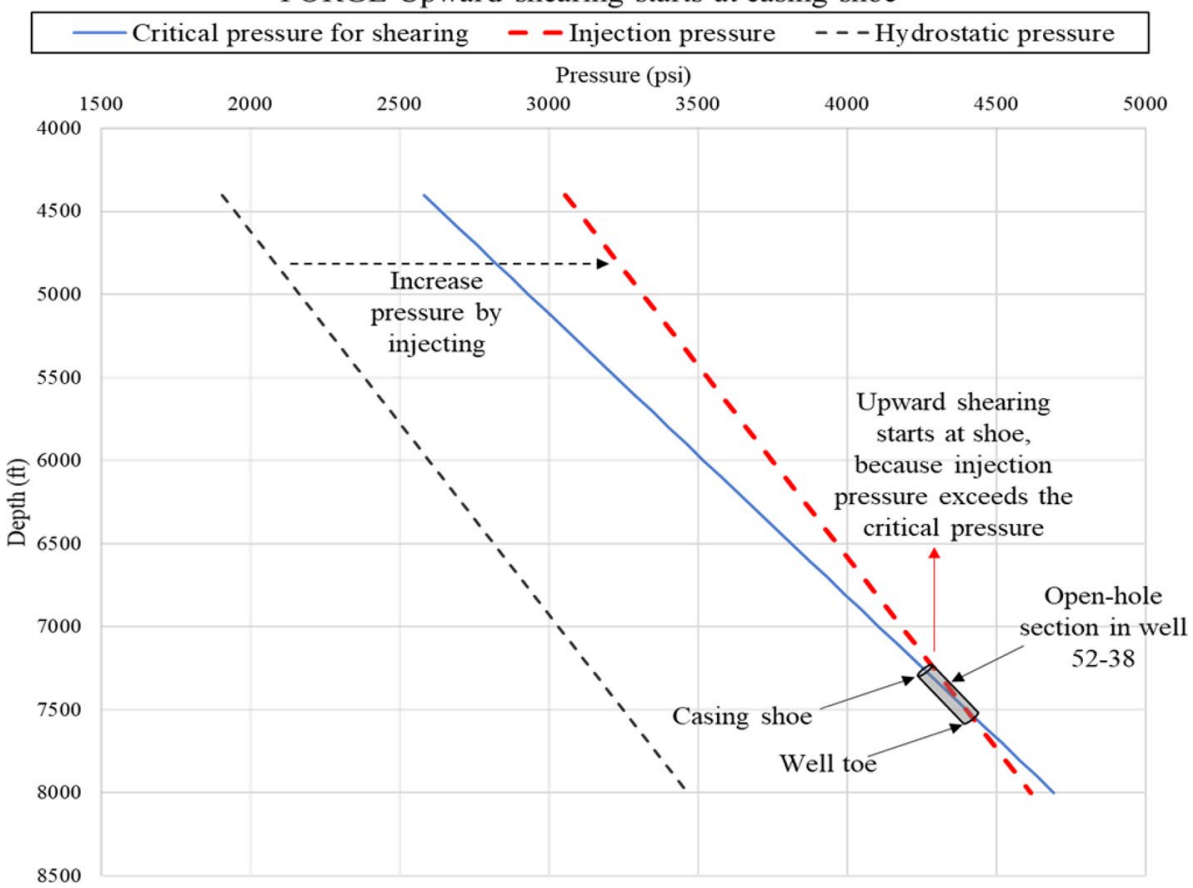

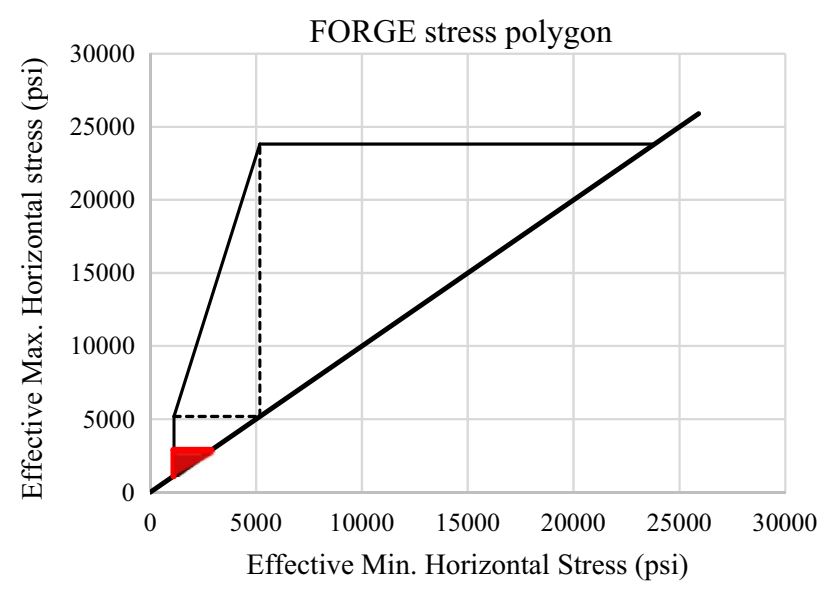

Fig. 3 Stress polygon based on the general stress ranges (black triangle). The red triangle shows the stress regime in the FORGE reservoir. The stress limits are computed using a friction coefficient of 0.82

stresses and depth, 0.5-2.0 is a suggested range for the horizontal-to-vertical stress ratio at depths below $1000 \mathrm{~m}$ $(3280 \mathrm{ft})$. Field stress states for seven EGS sites collected by Xie et al. (2015) confirm this range. The polygonal stress plot in Fig. 3 shows the stress conditions at the Utah FORGE site. The entire stress range covered here is represented as a triangle in the lower left, and two more auxiliary dashed lines are added to distinguish normal faulting (NF), strike-slip (SS) and reverse faulting (RF) stress regimes. The polygon is prepared using methodologies developed by Zoback et al. (2003) and a friction

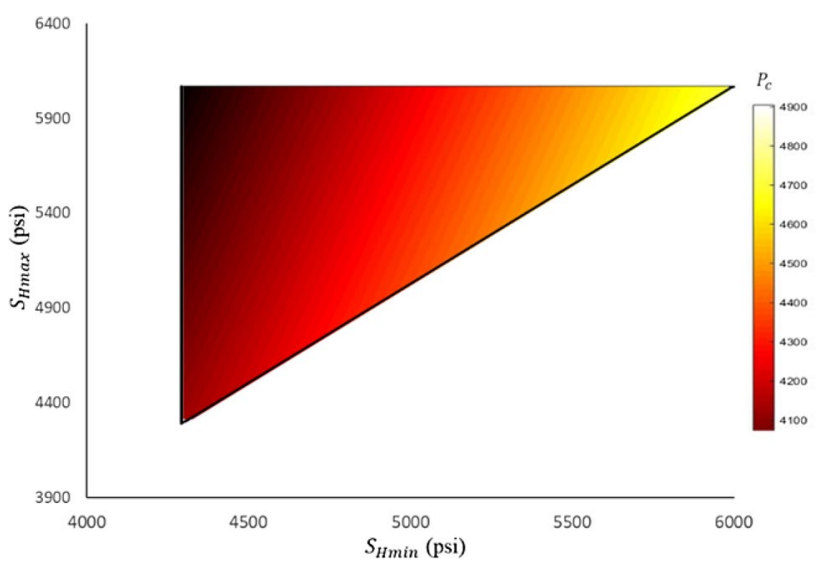

Fig. 4 Critical pressure, $P_{\mathrm{c}}$, for shearing activation computed using Eq. (2) at a depth of $7400 \mathrm{ft}$ in well 58-32

coefficient of 0.82 . The friction coefficient was determined from FORGE reservoir laboratory core experiments that sheared mechanically pre-induced fractures. The Milford Utah FORGE field is located in the normal stress regime (red triangle in Fig. 3). Figure 4 shows the computed critical pressure results using Eq. (2). In Fig. 4, near the upperleft up corner, where $\sigma_{2}$ is at its highest limit, the lowest fluid pressure is required to reactivate slippage along the NE-SW fracture set in well 58-32. In contrast, at the bottom-right corner, the highest fluid pressure is needed to initiate slippage. Therefore, greater energy consumption is needed to pump in fluid and achieve breakdown. Generally, an anisotropic stress field (higher differential stress) 
Fig. 5 A snapshot of the Formation MicroImager (FMI) log acquired from both runs, before and after the DFIT testing. This snapshot just shows a small section of the openhole. This is a multi-pad resistivity tool that provides a high-resolution reconstruction of the wellbore, highlighting compositional changes, porosity, breakouts and fracturing through resistivity contrast. To the right of each $\log$ are the dips and azimuths

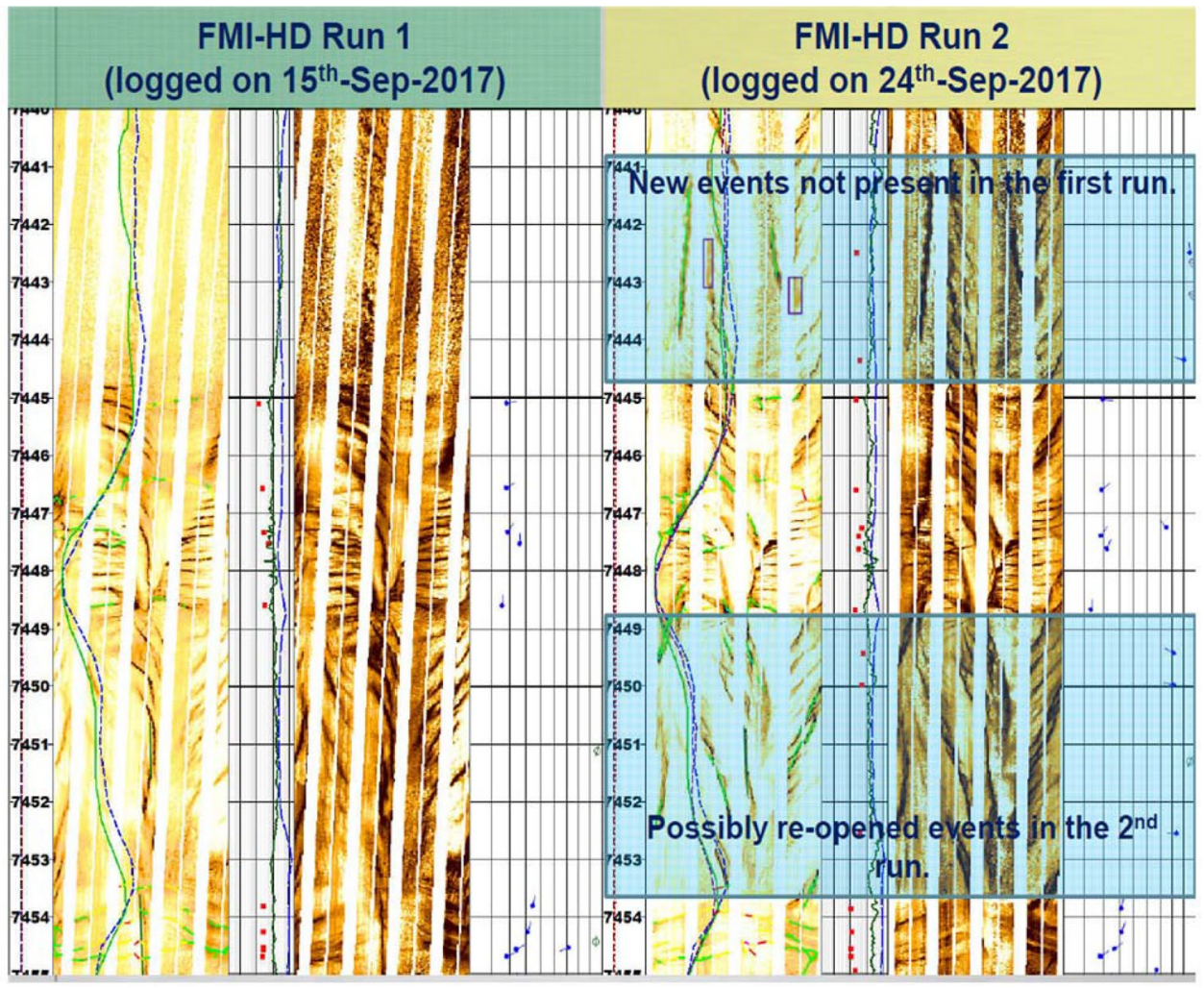

requires a lower injection pressure to initiate shearing on a natural fracture (Zoback et al. 2003).

Logging surveys were carried out in well 58-32 before and after the diagnostic fracture injection testing (DFIT $\left.{ }^{\mathrm{TM}}\right)$. The first logging runs were a standard triple combo suite (gamma ray and caliper, neutron porosity and bulk density and resistivity) followed by a dipole sonic imager (DSI) and a Formation MicroImager (FMI). These were conducted in the openhole section before production casing was run, from the surface casing shoe to the bottom of the hole, i.e., from 2175 to $7536 \mathrm{ft}$ MD. Production casing was set to $7386 \mathrm{ft}$ in advance of injection testing. After the injection test, a second set of sonic (DSI) and FMI logs was run in the remaining openhole section, from 7386 to $7536 \mathrm{ft}$ MD.

Comparisons between the first and second FMI logs show that there are populations of induced/reactivated, vertical, sub-vertical and gently dipped fractures/natural fractures (see Fig. 5). The drilling-induced or stimulated tensile fractures are concentrated in a north-northeast orientation and steeply dip (to the east and west). Other reactivated natural fractures exist which could be developed due to either shearing or mixed mode mechanisms (tensile and shear fracturing). These fractures are mostly wide open and sub-vertical. They are mostly northeast-southwest-oriented fractures.

\section{Diagnostic Fracture Injection Testing (DFIT ${ }^{\mathrm{TM}}$ )}

A Diagnostic Fracture Injection Test (DFIT ${ }^{\mathrm{TM}}$ ), also colloquially and sometimes inaccurately called Pre-Frac, Injection Falloff, Data-Frac or minifrac, is a pressure transient test used to obtain reservoir information such as closure pressure, reservoir pressure, permeability and skin (Barree et al. 2015; Ramurthy et al. 2002). After filling the wellbore, the target zone is pressurized at a low to moderate rate; the pressure will increase until initiation and breakdown occur. Breakdown can be recognized either by a drop in pressure as a new fracture initiates; otherwise reopening/extension is recognized by a plateau in pressure. A constant rate is held for a couple of minutes, and then, pumping is stopped. The pressure immediately drops at the surface to the instantaneous shut-in pressure (ISIP). The pressure after shut-in is monitored. Enough fluid should be injected under fracturing conditions so that the desired parameters can be measured (Barree et al. 2015).

Cornet and Bérard (2003) proposed that reliable estimation of the minimum principal stress in the field is derived by the maximum pressures during large-volume injection and relatively high-rate injections where reopening pressure is reached. They believed that testing with low fluid rates and volumes gives unrealistic estimations of 
the minimum principal stress. Valley and Evans (2007) assume that the maximum pressure provides a direct measurement of the minimum principal stress at the casing shoe-this ignores stress concentration. Their proposed methodology assumes the following conditions:

1. The maximum pressure is controlled by tension and not shearing.

2. Near-wellbore pressure drops (i.e., entrance losses) due to the focusing of flow are negligible.

3. The minimum stress prevailing at the time of maximum pressure reflects the ambient stress and is not elevated by poroelastic effects.

G-function, $\log -\log$ (diagnostic) and Bourdet plots with derivatives taken with respect to shut-in time, superposition time and time-integrated pressure are methods that can be used to interpret the pressure transient behavior and flow type (Barree et al. 2009, 2013; Bourdet et al. 1989; Marongiu-Porcu et al. 2011). Plots of pressure versus the square root of time and G-function are two major methods for diagnosing fracture-closure pressure (Nolte 1997; Nolte and Smith 1981). The leakoff rate scales with the inverse of the square root of time after solving the diffusivity equation for one-dimensional leakoff from a constant pressure boundary (Howard and Fast 1957; Liu and Ehlig-Economides 2016). Leakoff leads to pressure decay scaling with the square root of time when coupled with a wellbore/fracture system of constant compliance. The G-function is a generalization of this concept that includes the effect of fracture propagation, which causes the duration of fluid loss to be different at each point along the fracture (McClure et al. 2016).

\section{Shear interpretation by DFIT analyses}

This section summarizes eight DFIT tests performed in well 58-32. In most of the tests, especially at higher injection rates, natural fracture-dependent leakoff (NFL) was observed. These effects can result from the shearing/reactivation of natural fractures intersecting the wellbore and associated shear dilatancy. The natural fracture-dependent leakoff (NFL) or pressure-dependent leakoff (PDL) and multi-closure behavior in injection test analysis result from leakoff that occurs due to a combination of mechanisms associated with leakoff in dilated or opened natural fractures and tensile fractures. The leakoff occurs due to both mechanisms at different pressures. In this study, DFIT test analysis and numerical simulations were undertaken to assess if hydraulic shearing of critically stressed natural fractures can cause multiple closures and complicate determining the minimum principal stress.

Natural fractures and faults are planes of weakness where fluid can penetrate in the absence of mud cake. Mud cake formed around a wellbore wall impairs the fluid entry. However, in well 58-32, because of the mud system, little or no mud cake was present. Therefore, fluid will penetrate in the natural fractures and shear/reactivate them if they are not healed/infilled. Drilling-induced tensile fractures were also present before the injection was undertaken. By increasing the pore pressure inside any of these fractures, the shear stress on the fracture can exceed the critical stress and induces failure. Using the relationships presented earlier, the critical stress for some of the natural fractures in the FORGE reservoir is estimated to be about 900-1200 psi above the static pore pressure (which is approximately hydrostatic). Based on the injection fluid pressure and rate, mixed mode fracturing (shear and tensile) can occur in the wellbore.

\section{FORGE DFIT pressure analysis}

Injection data obtained from eight tests in well 52-38 were analyzed using KAPPA ${ }^{\mathrm{TM}}$ - Saphir test interpreter. G-function, diagnostic $(\log -\log )$ and square root of time plots were built, interpreted, and analyzed for each test. Numerical simulations were performed using XSite ${ }^{\mathrm{TM}}$ developed by ITASCA Consulting Group. XSite ${ }^{\mathrm{TM}}$ is a three-dimensional hydraulic fracturing numerical simulation software including propagation in naturally fractured reservoirs with deterministically or stochastically generated discrete fracture networks (DFNs). The model incorporates fully coupled hydromechanical simulations.

For analyzing the effect of shearing mechanisms happening alongside natural fractures on DFIT pressure behavior, three generic simulations were performed. Two simulations incorporated a single preexisting fracture in two different directions and one simulation included no fractures. These were performed to investigate the effect of natural fractures intersecting the wellbore on the pressure behavior and closure pressure estimation. In the simulations, the fluid is single component, single phase, with constant viscosity and compressibility. The simulations were performed under the primary estimated in situ stress conditions. Table 2 provides the data used in the simulations. Because of high computation time, simulations were performed for injection times of seconds only. The simulated pressure data were also analyzed with KAPPA ${ }^{\mathrm{TM}}$ - Saphir test interpreter. The analyzed results and interpretations of the field tests and numerical simulations were also compared.

Figures 6 and 7 show the G-function and the log-log plot analysis for Cycle \#2 (refer to Fig. 1 and Table 1) performed in well 52-38. In this cycle, $2.8 \mathrm{bbl}$ of freshwater was injected into the barefoot section of the wellbore at a rate of $0.4 \mathrm{bpm}$. The G-function and diagnostic (log-log) plots show that there is a natural fracture-dependent leakoff (NFL) behavior in this test. The NFL behavior on the G plot is presented by humps in the $G \mathrm{~d} p / \mathrm{d} G$ versus $G$ plot. 
Table 2 Base settings used in the all numerical simulations

\begin{tabular}{llllll}
\hline Parameter & Unit & Value & Parameter & Unit & Value \\
\hline Poisson's ratio $(v)$ & - & 0.25 & Young's modulus $(\mathrm{E})$ & $\mathrm{psi}$ & $6.5 \times 10^{6}$ \\
Fluid viscosity $(\mu)$ & $\mathrm{cp}$ & 1 & Porosity $(\phi)$ & $\%$ & 1 \\
Fluid density & $\mathrm{lb} / \mathrm{gal}$ & 8.34 & Rock density & $\mathrm{lb} / \mathrm{ft}^{3}$ & 165.4 \\
Fluid bulk modules & $\mathrm{psi}$ & 319,083 & $\mathrm{UCS}$ & $\mathrm{psi}$ & 25,380 \\
Fluid compressibility & $\mathrm{psi}^{-1}$ & $3.158 \times 10^{-6}$ & Tensile strength & $\mathrm{psi}$ & 2000 \\
Fracture toughness & $\mathrm{psi} \mathrm{in}^{0.5}$ & 910 & $\sigma_{v}$ & $\mathrm{psi}$ & $8360(1.13 \mathrm{psi} / \mathrm{ft})$ \\
Flat joint friction angle & $\circ$ & 26 & $\sigma_{\text {Hmax }}$ & $\mathrm{psi}$ & $5700(0.77 \mathrm{psi} / \mathrm{ft})$ \\
Permeability & $\mu \mathrm{D}$ & 30 & $\sigma_{h \min }$ & $\mathrm{psi}$ & $4600(0.62 \mathrm{psi} / \mathrm{ft})$ \\
Biot's coefficient & - & 1 & $\sigma_{\text {Hmax }}$ direction & $\circ$ & 25 \\
Fracture dip direction & $\circ$ & 25 and 60 & Normal stiffness & $\mathrm{psi} / \mathrm{ft}$ & $1.026 \times 10^{7}$ \\
Fracture dip angle & $\circ$ & 80 & Shear stiffness & $\mathrm{psi} / \mathrm{ft}$ & $1.41 \times 10^{6}$
\end{tabular}

Fig. 6 A G-function plot for Cycle \#2. It is difficult to pick the closure using the GdP/ $\mathrm{dG}$ plot. Two possible closure points: point 1 (shut-in = closure) and point 2

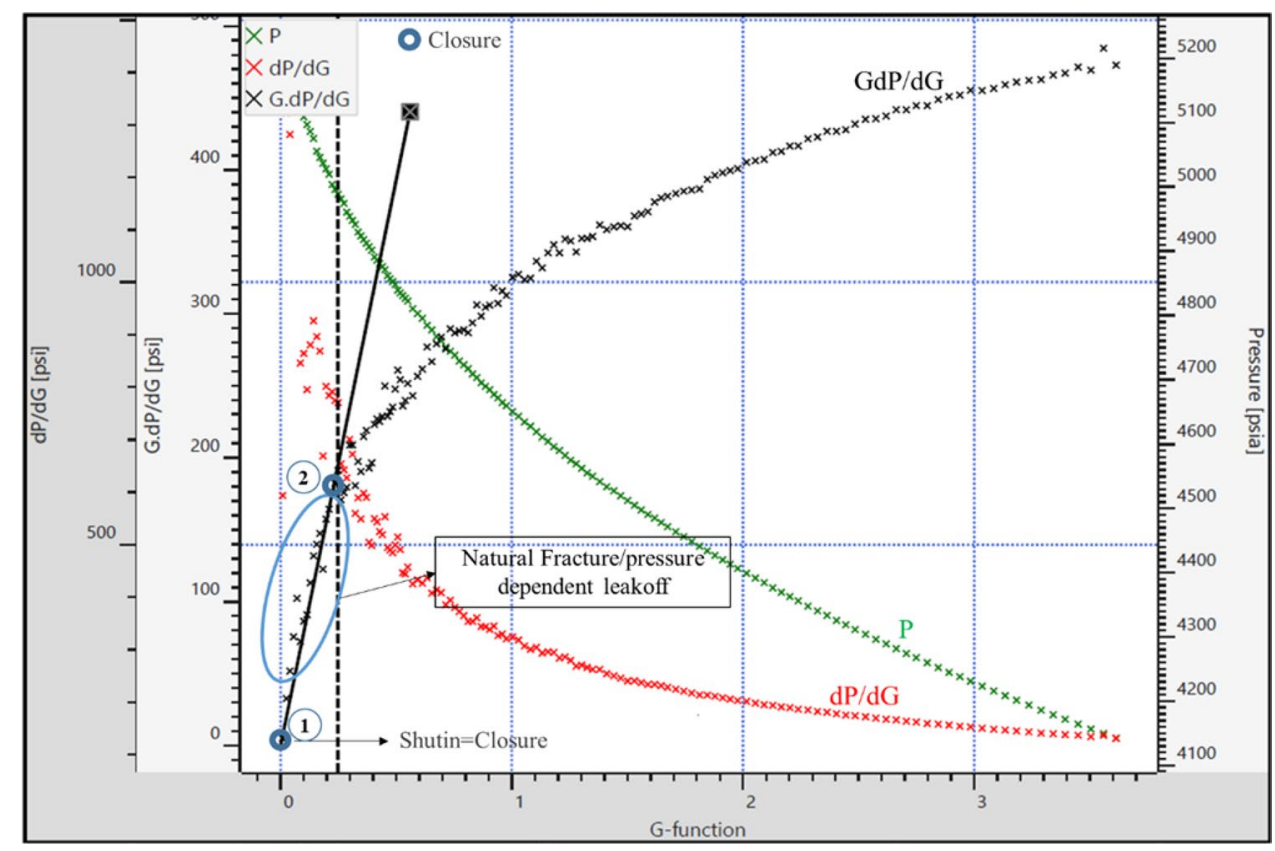

Since recoding time after shut-in is not long enough, negative slope in both of the graphs is not recorded. Because of the impermeable rock matrix, the curves and the pressure changes after shut-in are mostly controlled by the flow in the natural fracture. In the G-function plot, determining the closure point is difficult, because the straight line does not last for a long time. Based on previous studies, in these types of G-function shape, closure pressure can be equal to shut-in pressure.

In some parts of the G-function curve, it is assumed that tip extension also occurs. However, for tip extension to occur the leadoff rate to the formation must be relatively low (slope of $1 / 4$ on a semilog derivative curve). During alleged tip extension, the pressure difference curve falls on the parallel $1 / 4$ slope line separated by 4 times the magnitude of the derivative in the $\log -\log$ plot. In Figs. 6 and
7, the test does not exhibit a low leakoff rate and the tip extension assumptions are not matched in this test.

The semilog drawdown derivative curve for the Cycle \#2 test (Fig. 7) departs from an early unit slope (fracture storage) and establishes a $1 / 2$ slope. The $1 / 2$ slope in the semilog drawdown derivative curve (Fig. 7) implies linear fracture flow. In the semilog drawdown derivative curve (Fig. 7), fracture linear flow is suggested at the end of NFL, with a $1 \frac{1}{2}$ slope of the parallel to pressure difference curve. However, in this case, because of the low-permeability rock, leakoff mostly occurs into the natural fractures.

Figures 8 and 9 show the G-function and the log-log plot analysis for another low rate injection test-Cycle \#3. In this cycle, $4.2 \mathrm{bbl}$ of freshwater was injected into the well at a rate of $0.4 \mathrm{bpm}$. The G-function and diagnostic (log-log) plots show that there is a natural fracture-dependent leakoff 
Fig. 7 Log- $\log$ diagnostic plot for Cycle \#2. The $1 / 2$ slope in the semilog drawdown derivative curve implies fracture linear flow. The reduction in the semi$\log$ drawdown derivative from a $1 / 2$ slope is representative of closure. Drawdown derivative is $(\Delta t \mathrm{~d} \Delta P / \mathrm{d} \Delta t)$, and semilog derivative refers to the Bourdet derivative
Fig. 8 A G-function plot for injection Cycle \#3. Two possible closure points: point 1 (shut-in $=$ closure) and point 2
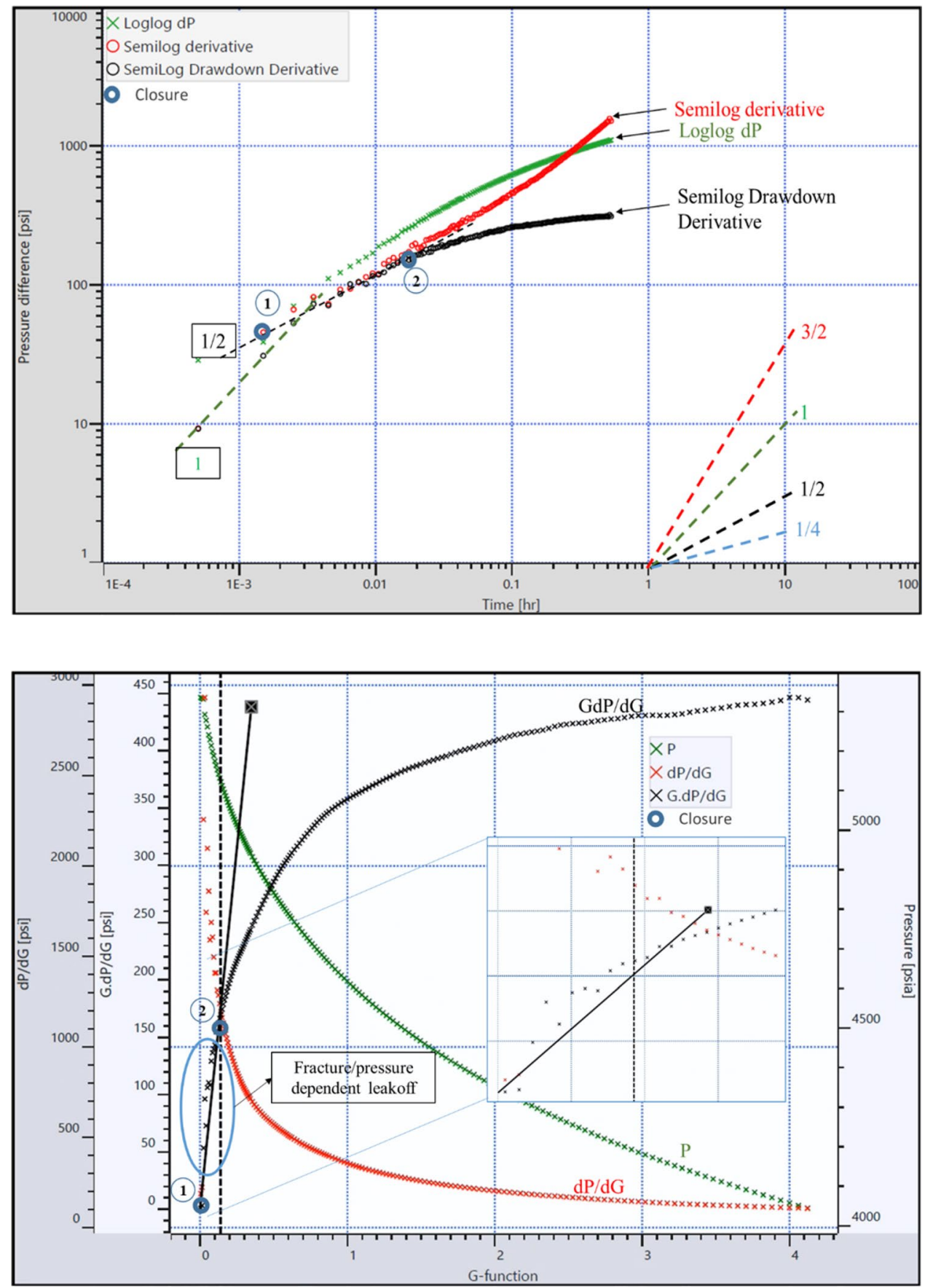

(NFL) behavior in this test. There are a couple of "humps" in the semilog derivative which are representative of NFL behavior. Since there is no straight line passing through the origin in the semilog derivative (Fig. 8), closure cannot be determined using this plot. Similar to Cycle \#2, closure pressure can be equal to shut-in pressure. Because of the impermeable rock matrix, the curves and the pressure changes after shut-in are mostly controlled by the flow in the natural fracture.

The semilog drawdown derivative curve for Cycle \#3 (Fig. 8) departs from an early unit slope (fracture and wellbore storage $^{1}$ ) and establishes a $1 / 2$ slope. The $1 / 2$ slope in the semilog drawdown derivative curve (Fig. 9) implies linear

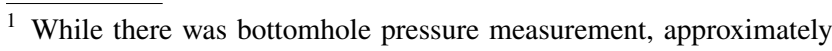
$147 \mathrm{ft}$ of openhole was in the system.
} 
Fig. 9 Log-log diagnostic plot for the DFIT test (Cycle \#3).

The type of the flow, before and after closure, is determined based on the slopes which are shown by dashed lines. The $1 / 2$ slope in the semilog drawdown derivative curve implies fracture linear flow. Drawdown derivative is $(\Delta t \mathrm{~d} \Delta P / \mathrm{d} \Delta t)$, and semilog derivative is referring to the Bourdet derivative

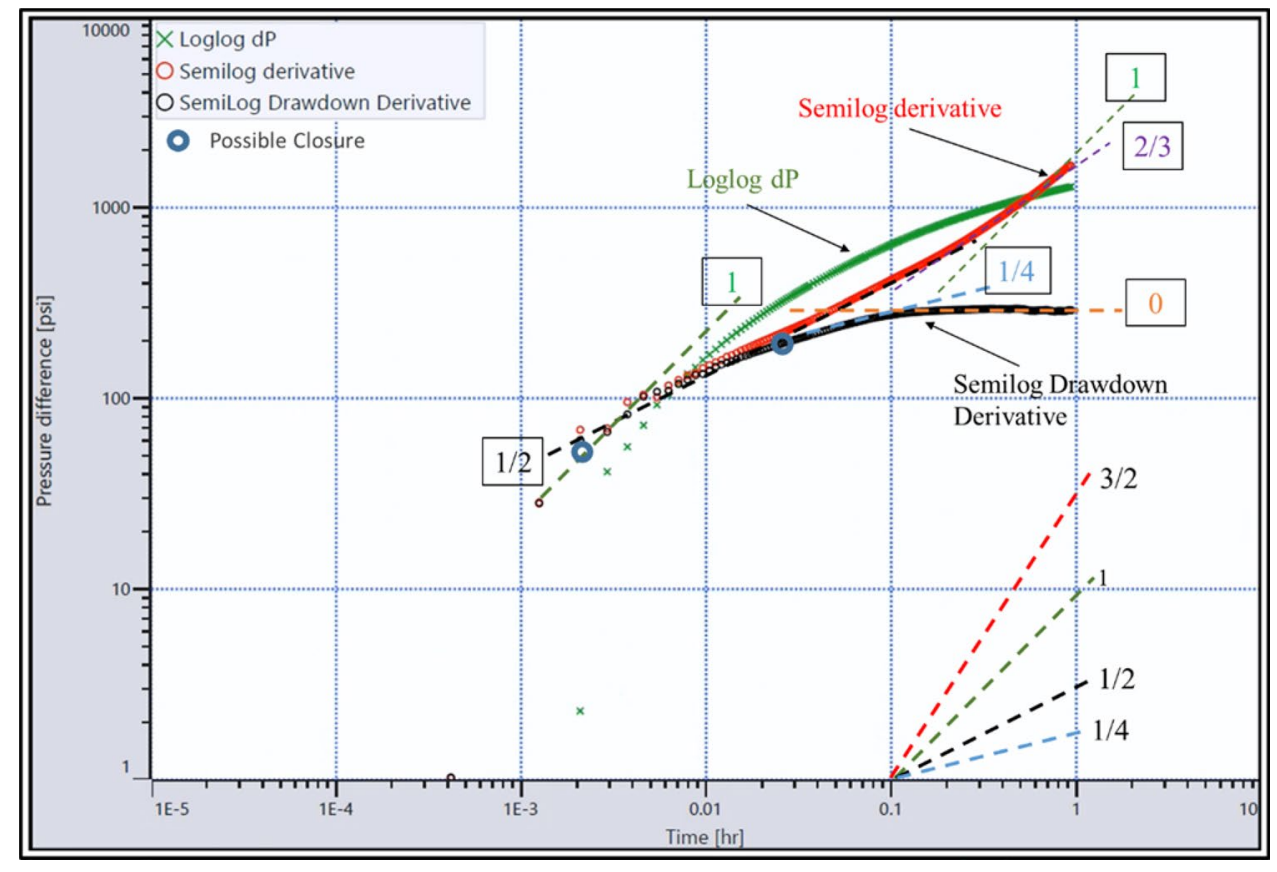

Fig. 10 A G-function plot for Cycle \#4. Natural fracturedependent leakoff (NFL) behavior happened after apparent closure



fracture flow. Fracture linear flow starts at the end of NFL, with a $1 / 2$ slope of the parallel to pressure difference curve. In this case, because of the low-permeability rock, leakoff only occurs into the natural fractures. Then, the semilog drawdown derivative curve (Fig. 9) departs from a $1 / 2$ slope and establishes a $1 / 4$ slope which may suggest bilinear flow. Zero slope at the end of the semilog drawdown derivative curve can be representative of radial flow due to leakoff in multiple natural fractures.
Figures 10 and 11 show the G-function and a diagnostic plot analysis for Cycle \#4 in well 58-32. In this cycle, $10 \mathrm{bbl}$ of freshwater was injected at a rate of $0.8 \mathrm{bpm}$. The G-function and diagnostic ( $\log -\log )$ plots show that there is natural fracture-dependent leakoff (NFL) behavior after the recorded closure signature. This test shows that probably after closure occurred in an induced tensile fracture, fracture-dependent leakoff occurred. 
Fig. 11 Log-log diagnostic plot for Cycle \#4. The type of the flow, before and after closure, is determined based on the slopes which are shown by dashed lines. The $1 / 2$ slope in the semilog drawdown derivative curve implies fracture linear flow before closure. In this case, the Bourdet derivative is not showing the closure. Drawdown derivative is $(\Delta t \mathrm{~d} \Delta P / \mathrm{d} \Delta t)$, and semilog derivative is referring to the Bourdet derivative

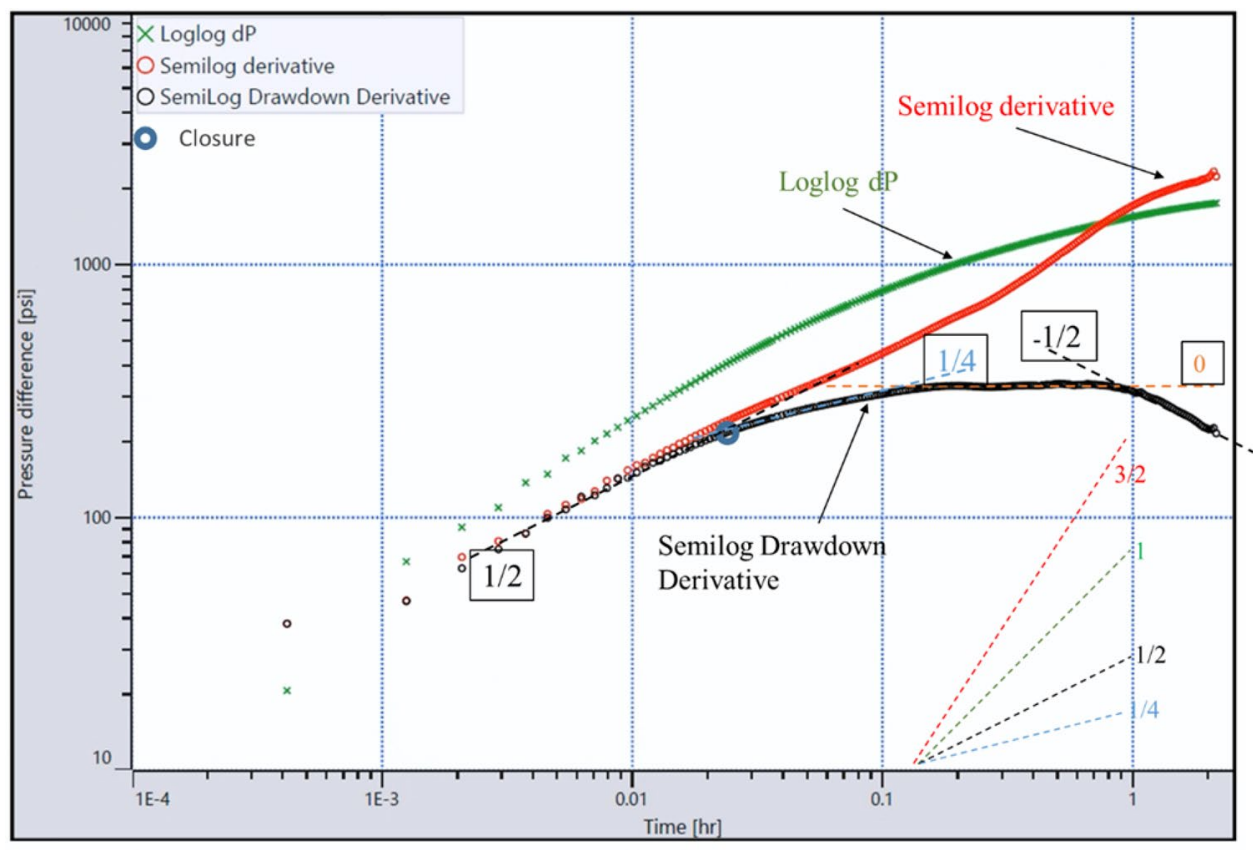

Fig. 12 A G-function plot for the DFIT test (Cycle \#5) with multi-closure events. The humps in the G-function plots correspond to three closing events, two of natural fractures and the other of the tensile fracture

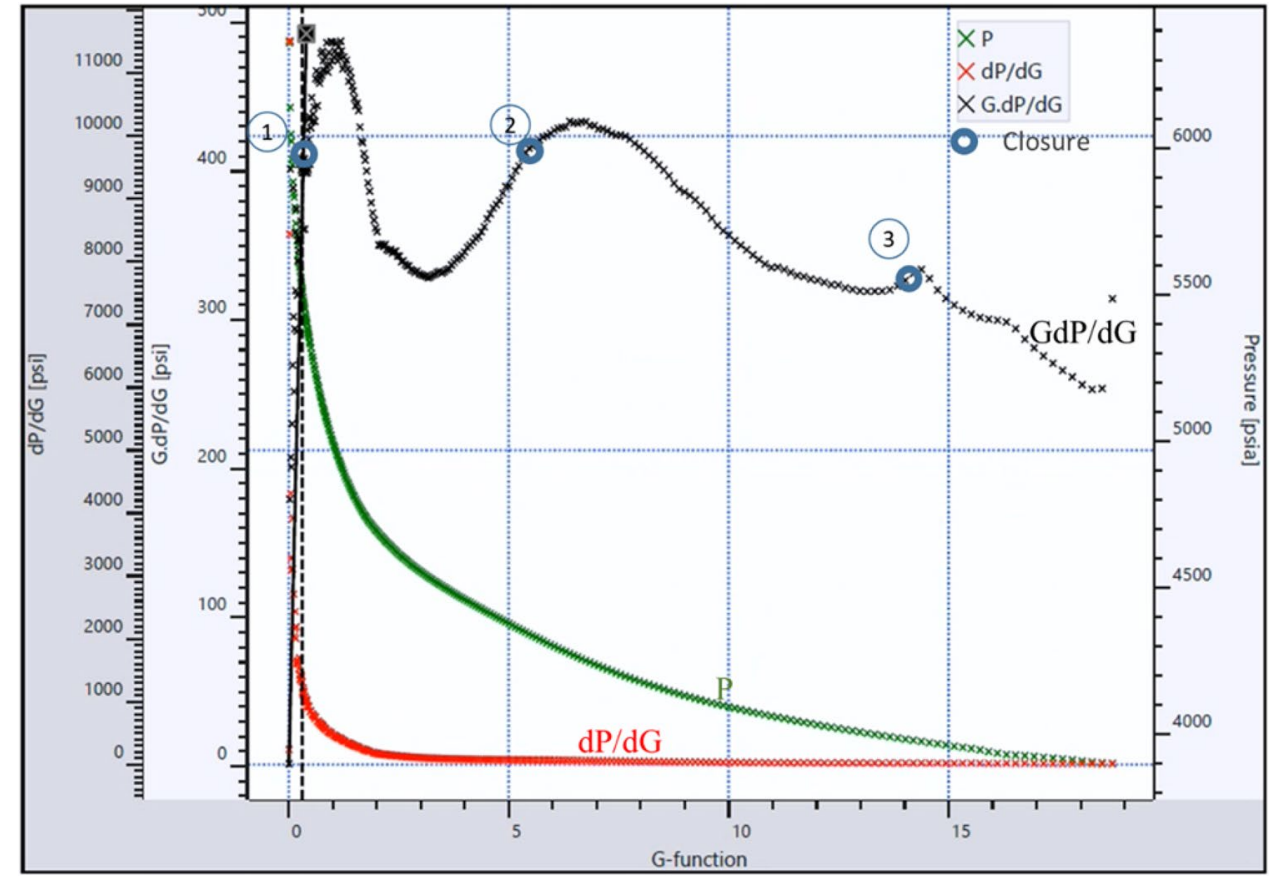

The semilog drawdown derivative curve for Cycle \#4 minifrac test (Fig. 11) establishes a $1 \frac{1}{2}$ slope, which implies a linear fracture flow. Then, the semilog drawdown derivative curve departs from a $1 / 2$ slope and establishes a $1 / 4$ slope which may exhibit a bilinear flow. The zero slope line (orange) can be representative of radial flow after the possible closure-one fracture system has been progressively closing, also rationalizing why bilinear flow was detected after dominant linear flow. Since the matrix rock is impermeable, this behavior could be attributed to flow from diverse natural fractures crossing the wellbore-or in the formation. This shows that a closure happened in the fracture subjected to the higher pressure compared to shearing or reactivation of natural fractures.

Figures 12 and 13 show the G-function and the log-log plots for Cycle \#5, a DFIT TM test in well 52-38. In this cycle, about $67.2 \mathrm{bbl}$ of freshwater was injected. The DFIT ${ }^{\mathrm{TM}}$ was initially at carried out at $5.8 \mathrm{bpm}$, and this was increased 
Fig. 13 Log-log diagnostic plot for Cycle \#5 with multi-closure events. After tip extension and a couple of PDLs in early time, there are 3 closure events. The $1 / 2$ slope is repetitive of fracture linear flow. Drawdown derivative is $(\Delta t \mathrm{~d} \Delta P / \mathrm{d} \Delta t)$, and semilog derivative is referring to the Bourdet derivative

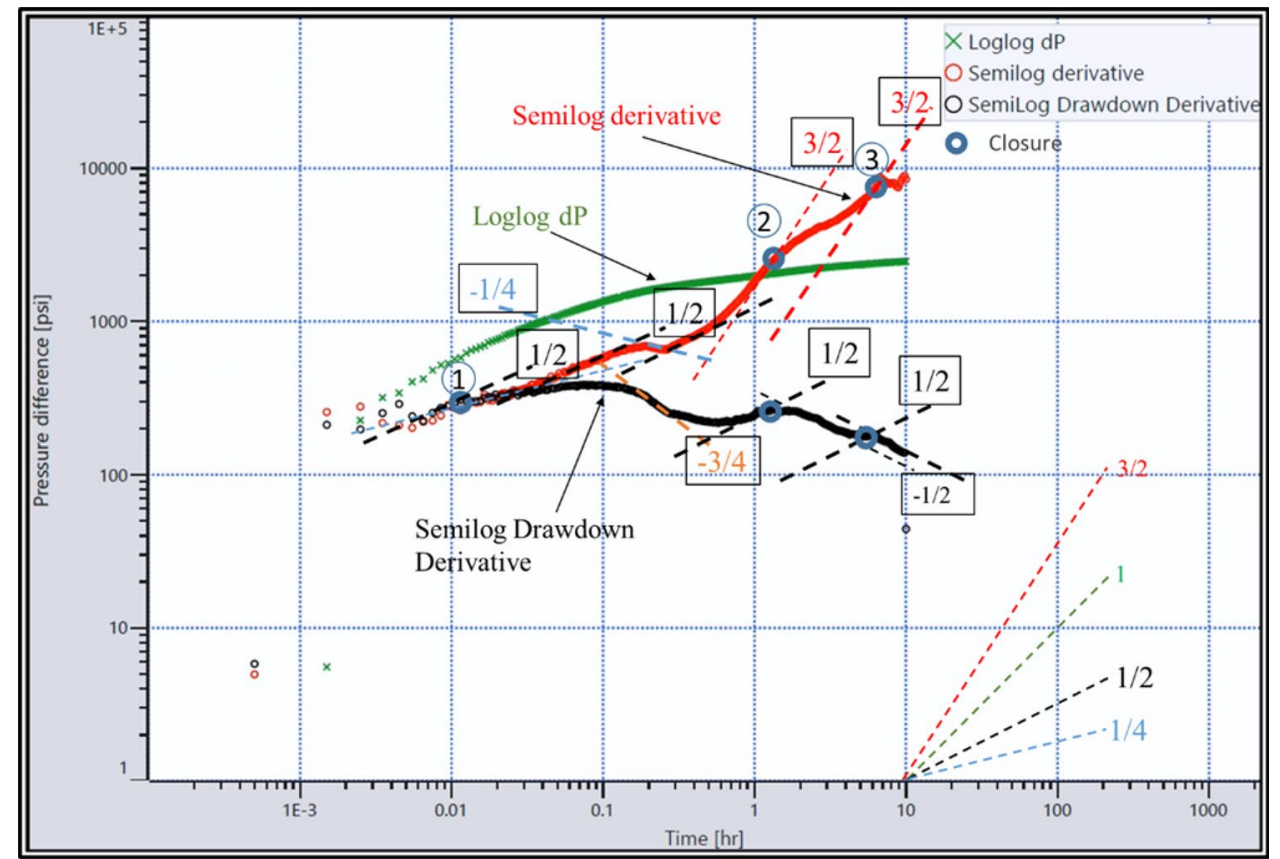

Table 3 Estimated closure pressure and time for Injection Cycles \#2 through \#6

\begin{tabular}{|c|c|c|c|c|c|c|c|c|c|}
\hline \multirow[t]{2}{*}{ Parameter } & \multicolumn{2}{|l|}{ Cycle \#2 } & \multicolumn{2}{|l|}{ Cycle \#3 } & \multirow{2}{*}{$\begin{array}{l}\text { Cycle \#4 } \\
\text { Closure }\end{array}$} & \multicolumn{2}{|l|}{ Cycle \#5 } & \multicolumn{2}{|l|}{ Cycle \#6 } \\
\hline & $\begin{array}{l}\text { Closure } \\
(1)=\text { shut- } \\
\text { in }\end{array}$ & $\begin{array}{l}\text { Possible } \\
\text { closure } \\
(2)\end{array}$ & $\begin{array}{l}\text { Closure } \\
(1)=\text { shut- } \\
\text { in }\end{array}$ & $\begin{array}{l}\text { Possible } \\
\text { closure } \\
(2)\end{array}$ & & Closure 1 & Closure 2 & Closure 1 & Closure 2 \\
\hline Closure pressure (psi) & 5179 & 4998 & 5330 & 5210 & 5372 & 5462 & 4383 & 4462 & 4319 \\
\hline Closure pressure gradient (psi/ft) & 0.70 & 0.67 & 0.72 & 0.70 & 0.72 & 0.73 & 0.59 & 0.60 & 0.58 \\
\hline Closure time (h) & 0.0155 & 0.0162 & 0.189 & 0.1925 & 0.0095 & 0.0368 & 1.1566 & 0.0032 & 0.029 \\
\hline
\end{tabular}

to $8.7 \mathrm{bpm}$ for $5 \mathrm{~min}$. In Fig. 12, after a couple of PDLs in early time, 3 closure events are recorded. The humps in the G-function plots, Fig. 12, correspond to two closing events, probably induced fractures close first and the other is for a sheared natural fracture. The third apparent closure was operational because of changing annulus pressure (changing in packer storage factor) when the pipe rams were closed. The points marked 1, 2 and 3 show a 1/2 slope on the semilog drawdown curve and a $3 / 2$ slope on the semilog derivative (Bourdet derivative) plot (Fig. 13). This is representative of fracture bilinear flow. A - 3/4 slope after the first closure exhibits a fracture bilinear flow.

The first fracture closure is identified by the departure of the semilog derivative of pressure in the G-function plot from the straight line. The negative slope after the first closure indicates that, at that pressure, as the fracture empties, the rate of leakoff relative to the remaining stored fluid (only in that fracture) accelerated and the pressure declined more rapidly. Once the pressure decreases to the value that the second fracture starts to close, there is large volume of fluid stored in the second fracture which starts to leakoff. The leakoff rate relative to the stored volume is small. Therefore, the rate of pressure decline is likewise small, and accordingly we see a second positive slope in the semilog derivative versus G-function. Again, as the second fracture empties, the rate of leakoff relative to the remaining stored fluid accelerates and the pressure declines more rapidly. Estimated closure pressures are summarized in Table 3.

Figures 14 and 15 show the G-function and the log-log plot analysis for Cycle \#6 in well 58-32. In this cycle, about $3.8 \mathrm{bbl}$ of freshwater was injected at $0.4 \mathrm{bpm}$. In Fig. 13, a couple of "humps" in the semilog derivative, as well as upward concavity in the primary $\mathrm{P}$ versus $\mathrm{G}$ plot, suggests what is referred to as NFL behavior. Figures 14 and 15 suggest that two closures occurred: at $0.0032 \mathrm{~h}(\mathrm{GC}=0.0477)$ and at $0.029 \mathrm{~h}(\mathrm{GC}=0.362)$. Estimated closure pressures and their associated times are presented in Table 3. In this cycle, the pumping rate and volume are relatively small, and the leakoff and closure pressure is significantly affected by previous DFIT test (Cycle \#5). Lower pressure in this cycle 
Fig. 14 A G-function plot for the DFIT test (Cycle \#6). A couple of "humps" in the semilog derivative, as well as, upward concave in the behavior primary $\mathrm{P}$ versus $\mathrm{G}$ exhibit PDL

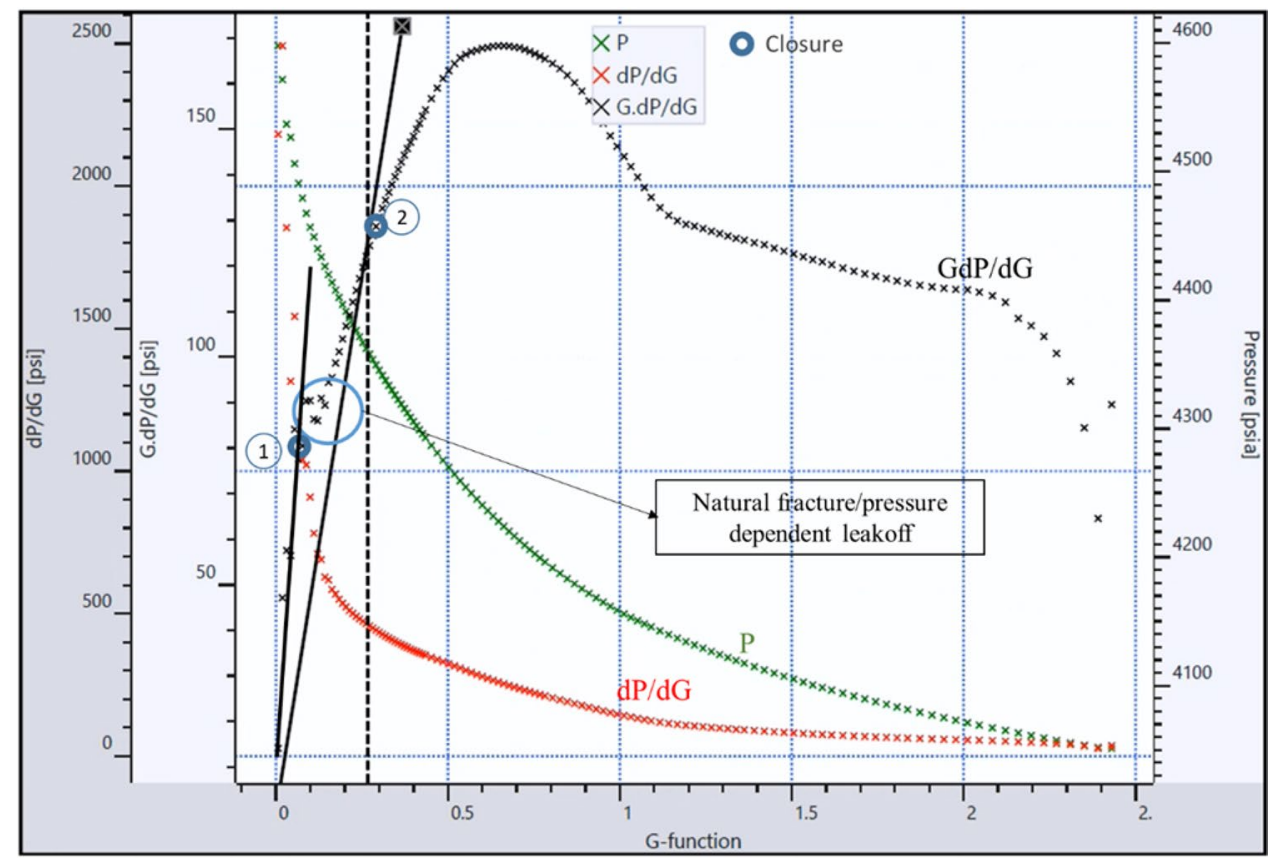

Fig. 15 Log-log diagnostic plot for the DFIT test (Cycle \#6). The log-log plot suggests that two closures occurred as the semilog drawdown derivative deviated from $1 / 2$ slope. Drawdown derivative is $(\Delta t$ $\mathrm{d} \Delta P / \mathrm{d} \Delta t$ ), and semilog derivative is referring to the Bourdet derivative

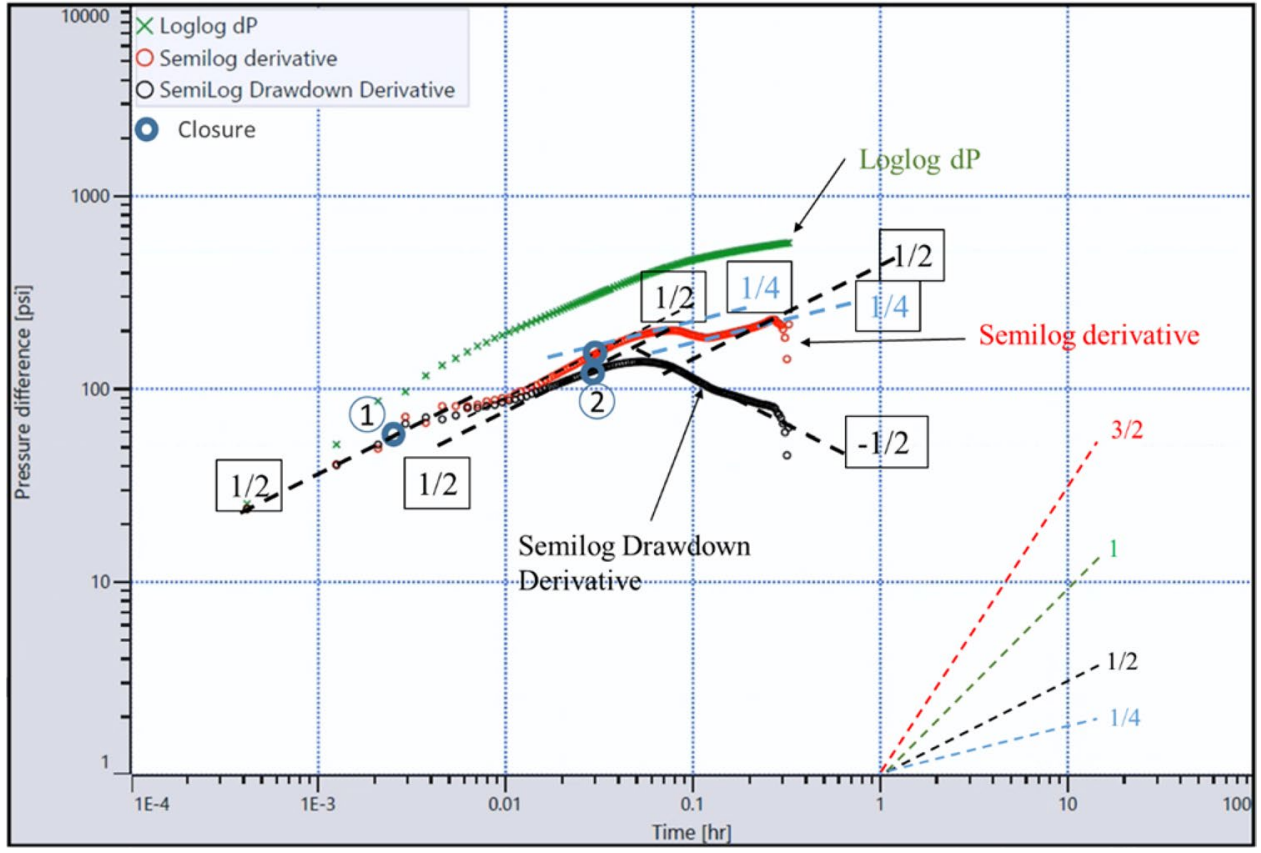

may be because of sheared natural fractures and residual aperture caused by previous tests.

\section{Numerical simulation of DFIT}

Figure 16 shows an $\mathrm{XSite}^{\mathrm{TM}}$ simulation of a DFIT ${ }^{\mathrm{TM}}$ test with a single natural fracture with a strike of $60^{\circ}$ and a dip of $80^{\circ}$. The direction of the maximum horizontal stress is $\mathrm{N} 25 \mathrm{E}$. The mechanical and reservoir properties used in this simulation are obtained from well logs and well tests, as well as laboratory tests (Table 2). In this study, we used the density log for estimating the overburden (vertical) stress. Based on the density log, the average vertical stress magnitude is $\sim 1.13 \mathrm{psi} / \mathrm{ft}$.

Fracture propagation starts by inflation of the natural fracture, and propagation bends toward a plane normal the minimum principal stress. This is classical wing crack behavior and is likely a dominant mechanism for finite fractures not 


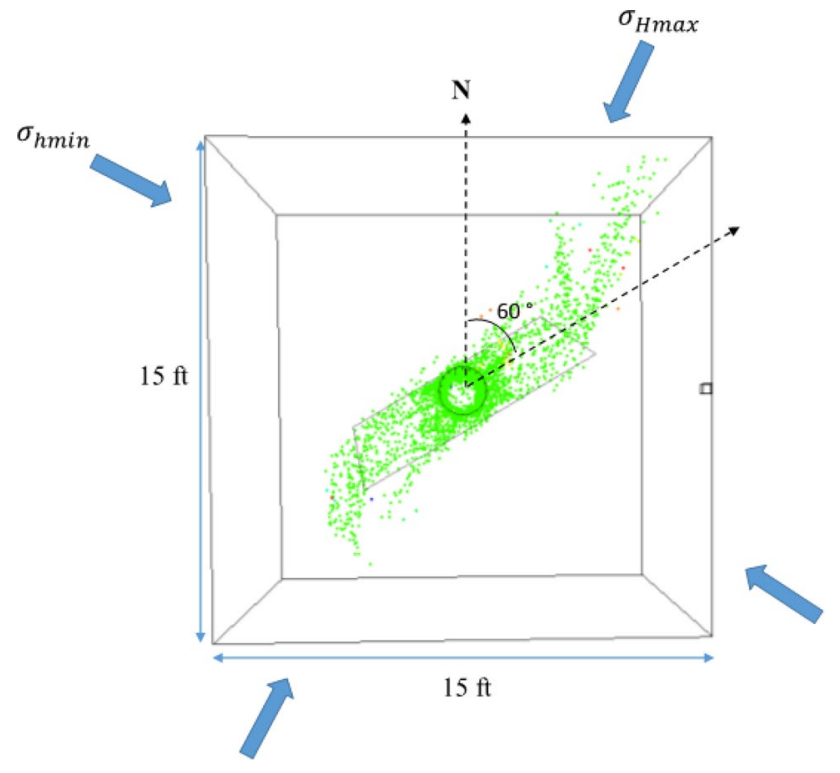

Fig. 16 Top view of fracture propagation (green dots) in the numerical simulation with a single preexisting fracture (gray rectangular crossing the wellbore) with dip direction of $60^{\circ}$. Fracture propagation starts from the natural fracture, and propagation bends toward a plane normal to the minimum principal stress

propagating in a principal plane. The injection pressure caused shearing. The reported stimulated area in shearing and tensile is $36.7 \mathrm{ft}^{2}$ and $59.5 \mathrm{ft}^{2}$, respectively. The relative shearing displacement of the fracture surfaces during the pumping is 0.0433 in with an opening of 0.0255 in. The pressure analysis for the simulation is shown in Figs. 17 and 18 . There is a similar behavior to Cycles \#2 and \#3. In the G-function and the log-log plots, two closure points are seen. Point 1 is representative of closure happening in the tensile fracture (bending toward maximum horizontal stress with direction of $25^{\circ}$ ) with pressure of $4600 \mathrm{psi}$ at a depth of $7400 \mathrm{ft}$ (equal to minimum horizontal stress). Point marked 2 which is more obvious than point 1 is representative of a preexisting fracture closure with pressure of $4495 \mathrm{psi}$. This shows that the obvious closure point in this simulation is representative of the natural fracture closure.

The semilog drawdown derivative curve (Fig. 18) departs from an early unit slope (storage) and establishes a $1 / 2$ slope (fracture linear flow). Then, it establishes a $1 / 4$ slope which exhibits bilinear flow. In this case, the semilog drawdown derivative and the pressure difference curves establish an early unit slope which indicates that transverse storage occurred during DFIT testing. This could be because of the bending of the propagation plane toward a plane normal the minimum principal stress. Basically, this simulation suggests natural fractures influence pressure behavior. In this case, simulation time after the shut-in was not enough to catch the negative slope in the log-log plot.

A second numerical simulation was performed using the same input parameters but with no fracture. The shape of the fracture is shown in Fig. 19. It propagates parallel to a plane containing the maximum horizontal stress. The pressure analysis for the simulation is shown in Figs. 20 and 21. In this simulation, the closure pressure is 4600 psi which is equal to the minimum principal stress in the simulation. The $\log -\log$ plot shows a fracture linear flow ( $1 / 2$ slope) before the closure. After closure, it establishes bilinear flow with slope of $1 / 4$ on a plot of semilog drawdown derivative. Finally, the
Fig. 17 A G-function plot for the DFIT test simulation with a single fracture striking at $60^{\circ}$. Two closure points are shown in the figures. Closure 1 refers to induced tensile fracture (bended section of Fig. 16), and closure 2 is showing the effect of the sheared natural fracture

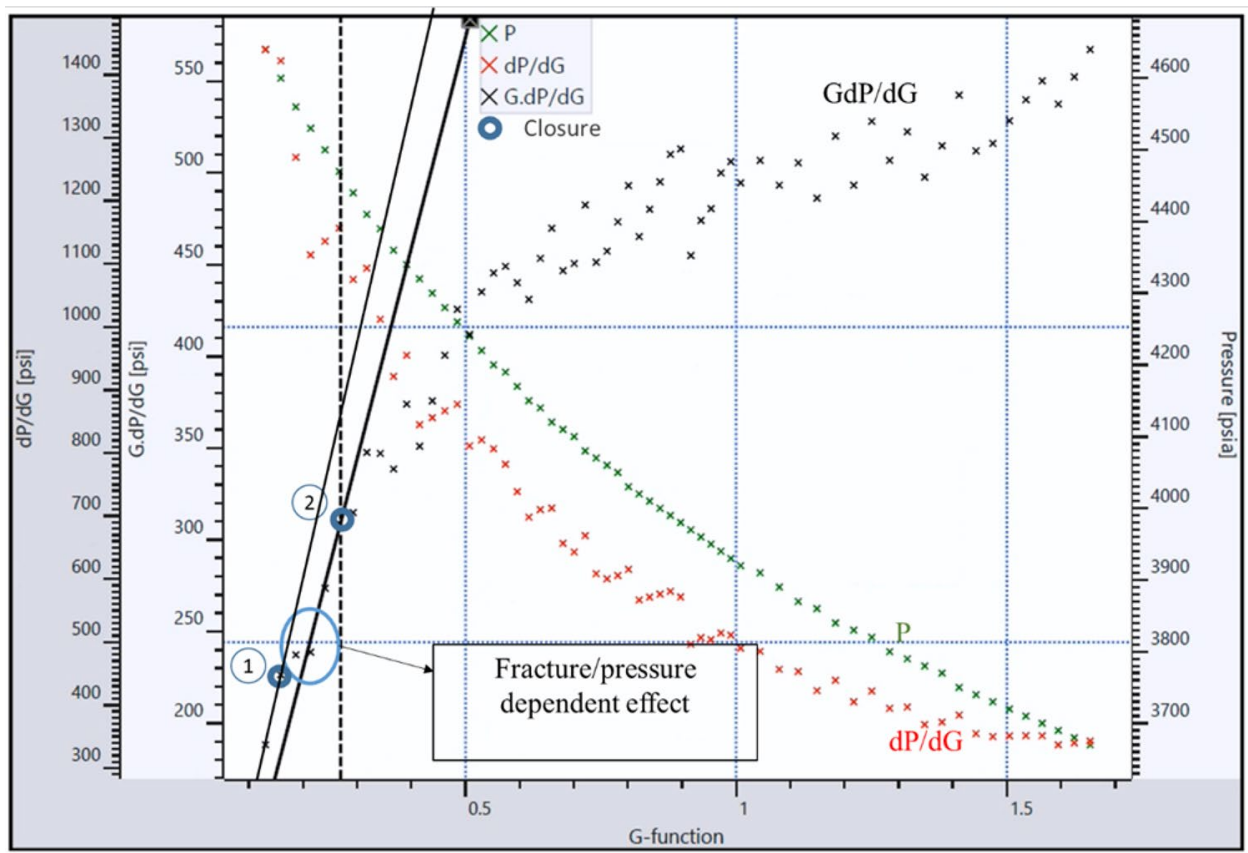


Fig. 18 Log-log diagnostic plot for the DFIT test simulation with a single fracture with dip direction of $60^{\circ}$. The semilog drawdown derivative curve departs from early unit slope (storage) and establishes a $1 / 2$ slope. Then, it establishes a unit slope which exhibits the storage behavior of the fractures. It is difficult to pick the closure point form this plot. Drawdown derivative is $(\Delta t \mathrm{~d} \Delta P / \mathrm{d} \Delta t)$, and semilog derivative is referring to the Bourdet derivative

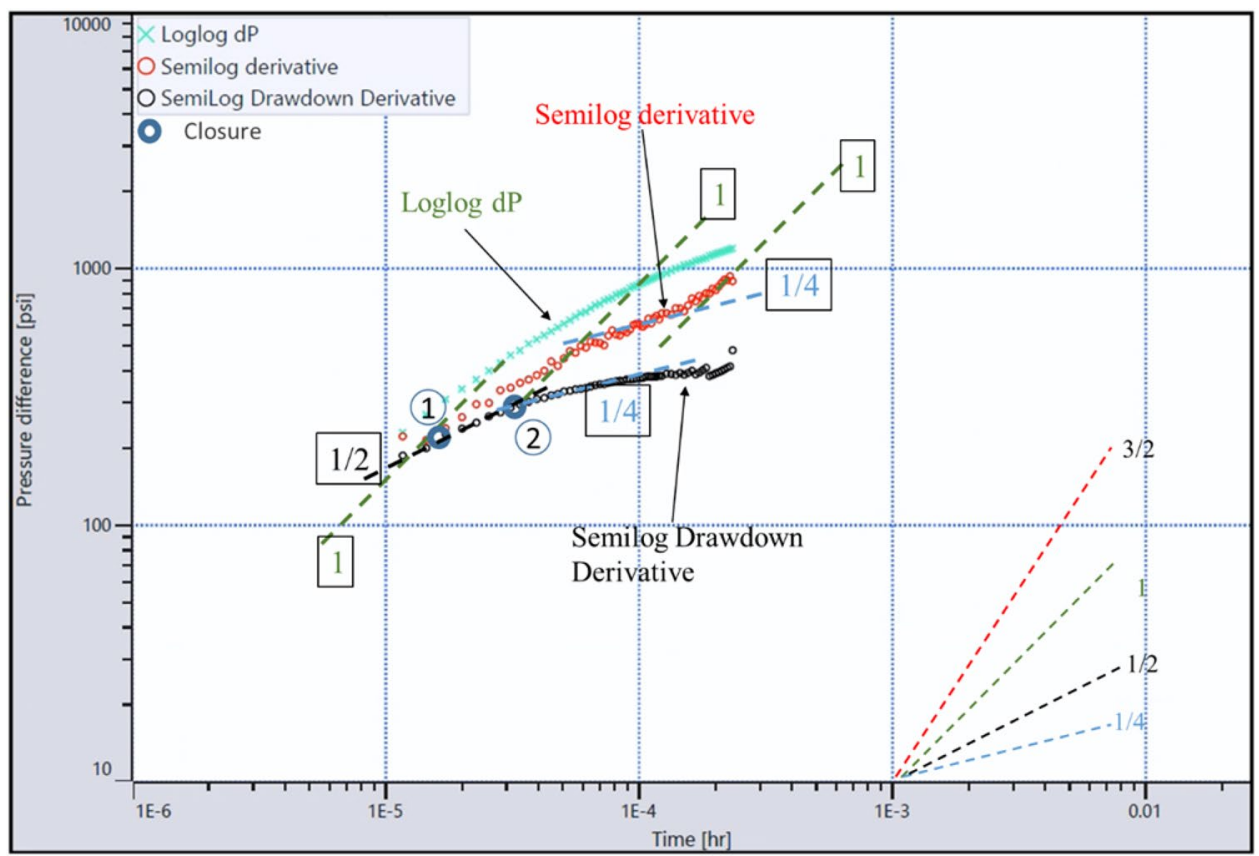

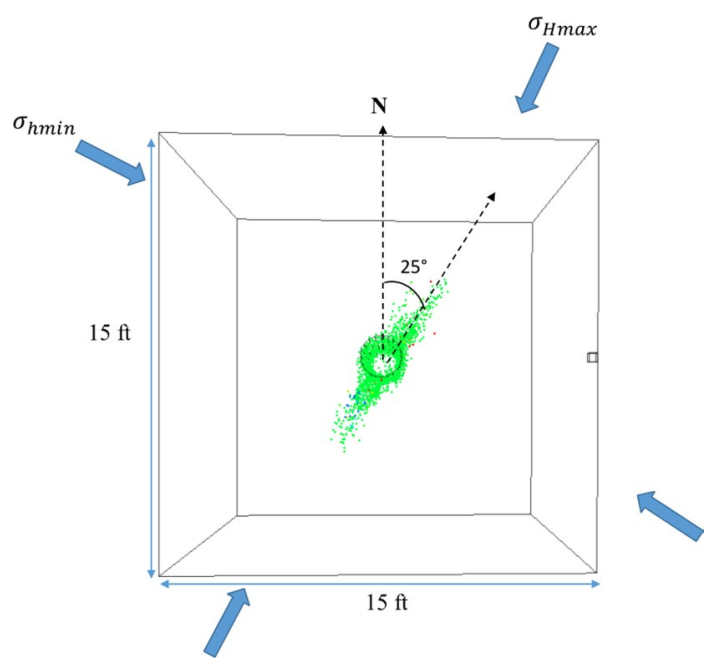

Fig. 19 Top view of tensile fracture propagation (green dots) in the numerical simulation with no natural fracture. Tensile fracture occurs in the direction of the maximum horizontal stress $\left(25^{\circ}\right)$

$-1 / 2$ slope is representative of fracture linear flow. Rationale for the bilinearity is uncertain and needs to be considered in future interpretations.

A third DFIT numerical simulation was performed using the same input parameters with a single natural fracture with a strike of N25E and a dip of $80^{\circ}$. Since the fracture is almost aligned with the maximum horizontal stress, lower injection pressure compared to the first simulation is needed to cause slip along the fracture. The shape of the fracture is shown in Fig. 22. The direction of the maximum horizontal stress is N25E. Fracture propagation starts from the natural fracture and propagates in the same direction. The reported stimulated area in shearing and tension is $39.7 \mathrm{ft}^{2}$ and $57.8 \mathrm{ft}^{2}$, respectively. The relative shearing displacement of the fracture surfaces during the pumping is 0.0724 in with opening of 0.0362 in.

The pressure analysis for the simulation is shown in Figs. 23 and 24. In this simulation, two closure pressures are shown in Figs. 18 and 19. Point 1 is representative of tensile fracture closure with pressure of $4600 \mathrm{psi}$ (equal to minim horizontal stress). Point 2 shows closure pressure for the preexisting fracture with pressure of $4390 \mathrm{psi}$ which is lower than the minimum principal stress (4600 psi at depth of $7400 \mathrm{ft}$ ). This shows that the closure pressure in this simulation is representative of the natural fracture closure. The injection pressure caused the natural fracture shearing.

In this case, the semilog drawdown derivative and the pressure difference curves lie together on a single unit slope which indicates transverse storage occurred during the test (Fig. 24). During transverse fracture storage, a secondary fracture is opened. The $-1 / 2$ slope on the semilog drawdown derivative curve (in log-log plot) represents fracture linear flow.

\section{Step rate test (SRT)}

A step rate test (SRT) with an extended shut-in was also conducted. In this cycle, $76.9 \mathrm{bbl}$ of freshwater was pumped in an increasing injection step rate test (SRT) at. A SRT is an alternative method used for evaluating the minimum in situ 
Fig. 20 A G-function plot for the simulation with no natural fracture. The closure pressure is $4600 \mathrm{psi}$ which is equal to the minimum principal stress in the simulation
Fig. 21 Log-log diagnostic plot for the DFIT test simulation with no natural fracture. The log-log plot shows a fracture linear flow ( $1 / 2$ slope) before the closer. After closure, it establishes bilinear flow with slope of $1 / 4$ on a plot of semilog derivative. Drawdown derivative is $(\Delta t \mathrm{~d} \Delta P / \mathrm{d} \Delta t)$, and semilog derivative is referring to the Bourdet derivative
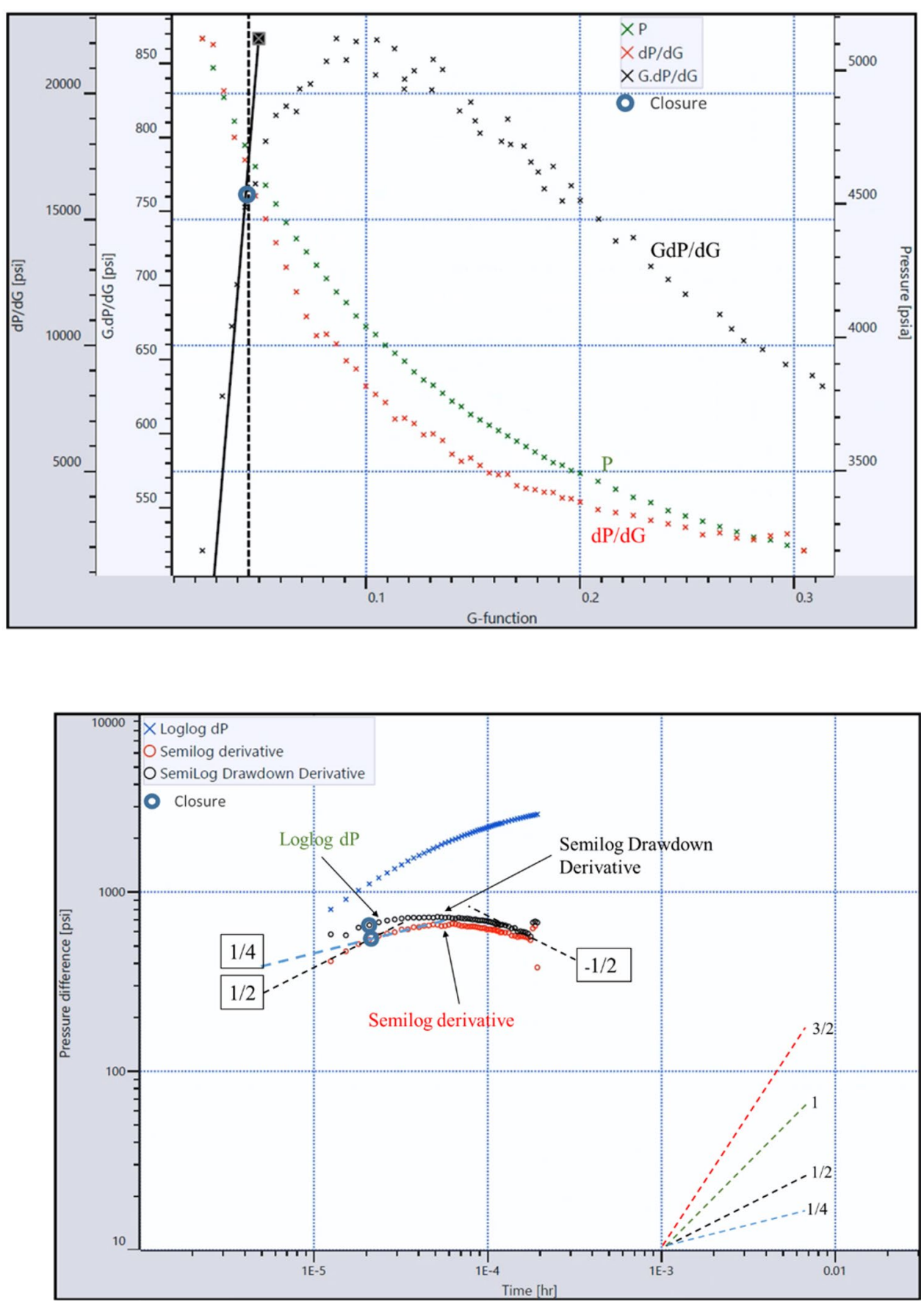

stress as a function of injection rate. Prior to tensile fracture opening, there is a significant increase in the pressure as the injection rate increases. After hydraulic fracture initiation, increasing the flow rate causes a reduced increase in the bottomhole pressure with rate. As shown in Fig. 25, there are no data points before breakdown or reopening of the fracture to precisely measure the closure pressure. However, the plot shows that the closure pressure can be inferred between the ranges of 5203-6156 psi (0.70-0.82 psi/ft). The message for future testing is lower rate measurements to show curvature of the pressure versus rate curve often seen when natural fractures are present. Notice that near-wellbore losses should also be quantified by a stepdown test.

\section{Injectivity index}

The injectivity index is a parameter that can be used to measure a well's potential or ability to accept fluid during injection. The definition of the injectivity (II) is: 


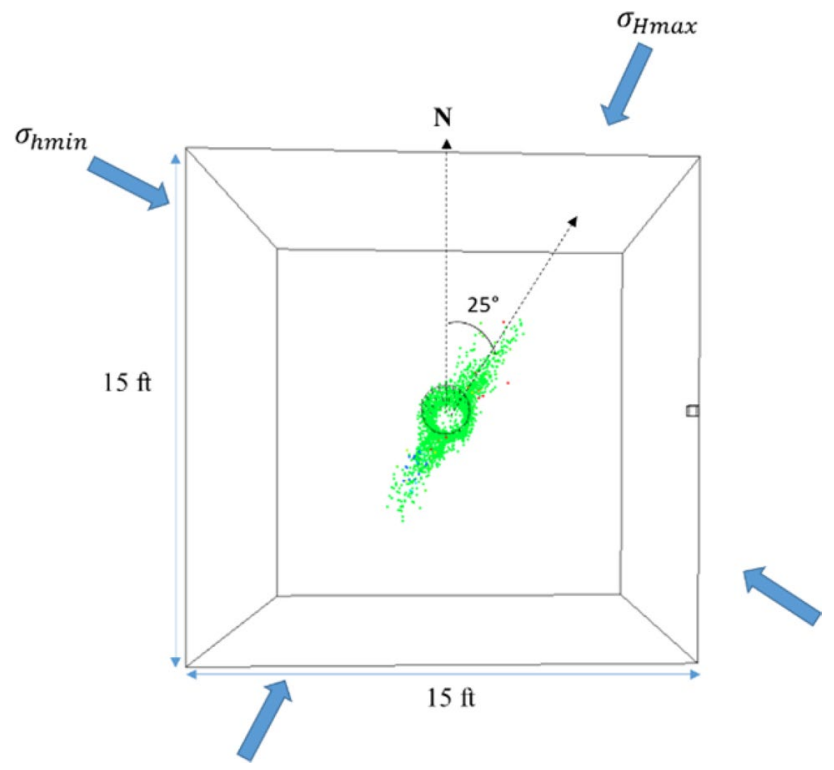

Fig. 22 Top view of fracture propagation (green dots) in the numerical simulation with a single preexisting fracture (gray rectangular crossing the wellbore) with a strike of $25^{\circ}$. Shear and tensile fractures occur in the direction of the maximum horizontal stress

$\mathrm{II}=\frac{q}{P_{\mathrm{wf}}-P_{i}}$

where $q$ is the injection rate, $P_{\mathrm{wf}}$ is the well flowing bottomhole pressure and $P_{i}$ is the reservoir pore pressure. In this section, injectivity analysis is used to address permeability retention possibly attributed to induced shearing of natural fractures.
The injectivity index for different flow rates obtained from the well 58-32 DFIT tests are shown in Fig. 26. At the same flow rate, specifically 0.4 and $0.8 \mathrm{bpm}$, the injectivity index increased in Cycles \#6 and \#7 compared to cycles $\# 2$ and \#3. At a rate of $0.4 \mathrm{bpm}$, the injectivity index during Cycle \#7 is about two times more than for Cycle \#2. Absolute change is inconsequential however. This behavior suggests that the tests performed in the well 58-32 caused retained permeability in the well during testing-albeit very modest. Also, as shown in Fig. 26, the injectivity index increased during the entire time of the testing. It is important to note that the magnitude of the injectivity index in later times is sensitive to the residual permeability of the natural fractures induced during the earlier tests.

\section{Conclusions}

This study reviewed the evidence that pumping fluid at high pressure would be expected to cause hydraulic fracturing (Mode I fracture), hydro-shearing (Mode II fracture) or a combination of both in low-permeability, naturally fractured reservoirs. A conventional critical stress analysis in the immediate vicinity of well 58-32 shows that the NE-SW fracture set is the most optimally oriented for shearing. The magnitude of the critical pressure was computed using Eq. (2) and is about 900-1200 psi (depending on the fracture friction coefficient) above the initial reservoir pore pressure. The shearing may activate with and upward propagation if the injection pressure profile first meets the critical pressure profile at the top of the openhole section (casing shoe).
Fig. 23 A G-function plot for the DFIT test simulation with a single fracture with a strike of $25^{\circ}$. It is difficult to determine the closure pressure from this plot

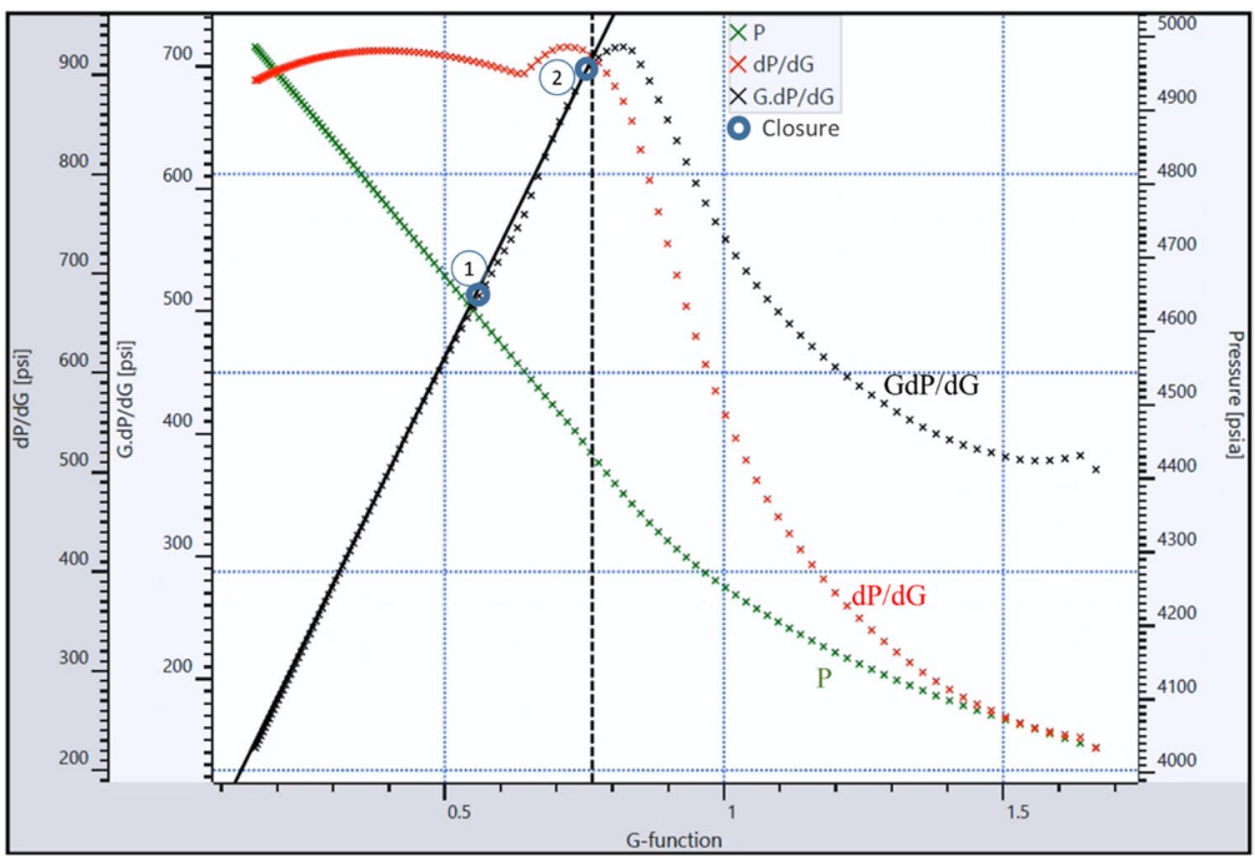




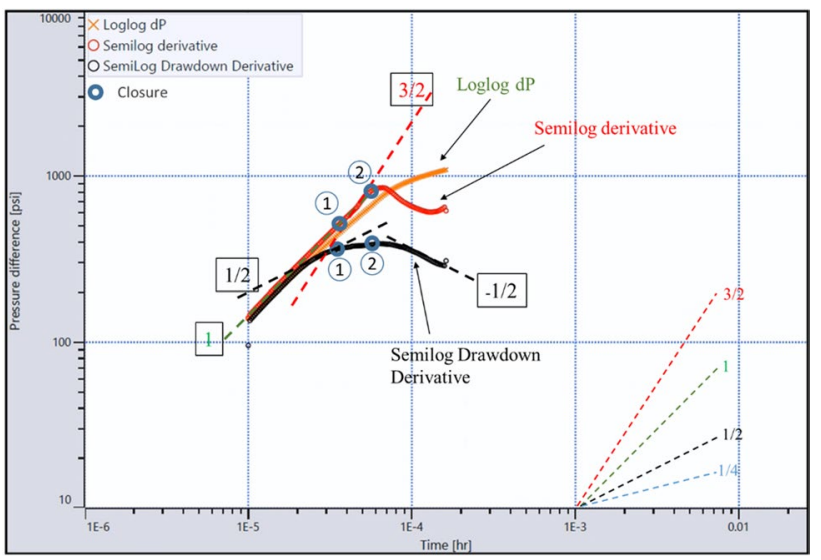

Fig. 24 Log-log diagnostic plot for the DFIT test simulation with a single fracture with dip direction of $25^{\circ}$. The semilog drawdown derivative curve departs from early unit slope (storage) and establishes a $-1 / 4$ slope. $-1 / 2$ slope on the semilog drawdown derivative curve (in log-log plot) represents fracture linear flow. Drawdown derivative is $(\Delta t \mathrm{~d} \Delta P / \mathrm{d} \Delta t)$, and semilog derivative is referring to the Bourdet derivative

Closure pressures obtained from injection testing can reflect shear fractures or discontinuities rather as well as tensile fractures. Inaccurate analysis of the type of failure can lead to an overestimation or underestimation of the minimum principal stress. A measured closure pressure does not always represent the minimum principal stress. Well 58-32 DFIT testing analysis indicates that the estimated minimum principal stress could have been underestimated. Natural fracture-dependent leakoff was observed in most of the tests. This behavior can be due to reactivation of natural fractures intersecting the wellbore. The counterpoint is that drillinginduced tensile fractures were present before the injection program. Multiple closure events are seen in injection Cycle

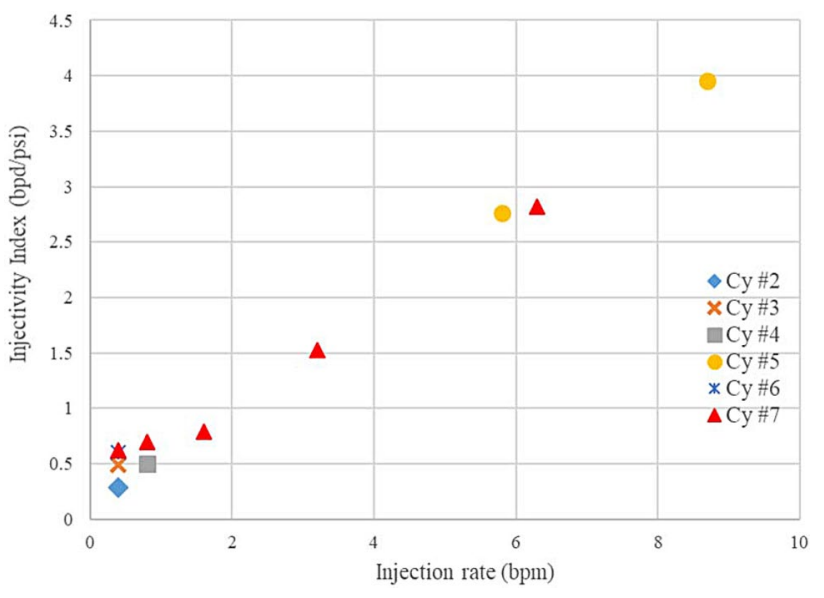

Fig. 26 Injectivity index for DFIT tests performed in Utah FORGE well 58-32. This plot shows the variation of the injectivity index versus the injection rate

\#5 because contributions from natural fractures and preexisting tensile induced fractures. Comparing FMI logs before and after injection shows either tensile, shearing or mixed mechanisms (tensile and shearing fracturing) occurred during the tests.

As has been advocated previously, better estimation of minimum principal stress in the field is derived by injecting at relatively high rates and pressure that achieve the conditions necessary for tensile breakdown. It is believed that injection testing with low fluid rate and volume gives unrealistic estimation of the minimum principal stress in low-permeability, fractured reservoirs. Numerical simulations and pressure analysis indicate that activation of natural (preexisting) fractures (dilation) could have occurred at lower pumping rates and injection pressures.
Fig. 25 A step rate test (SRT) with an extended shut-in was conducted to determine reservoir permeability and closure pressure (Cycle \#7). In this cycle, $76.9 \mathrm{bbl}$ freshwater was pumped in a step rate test (SRT) where rate progressively increased

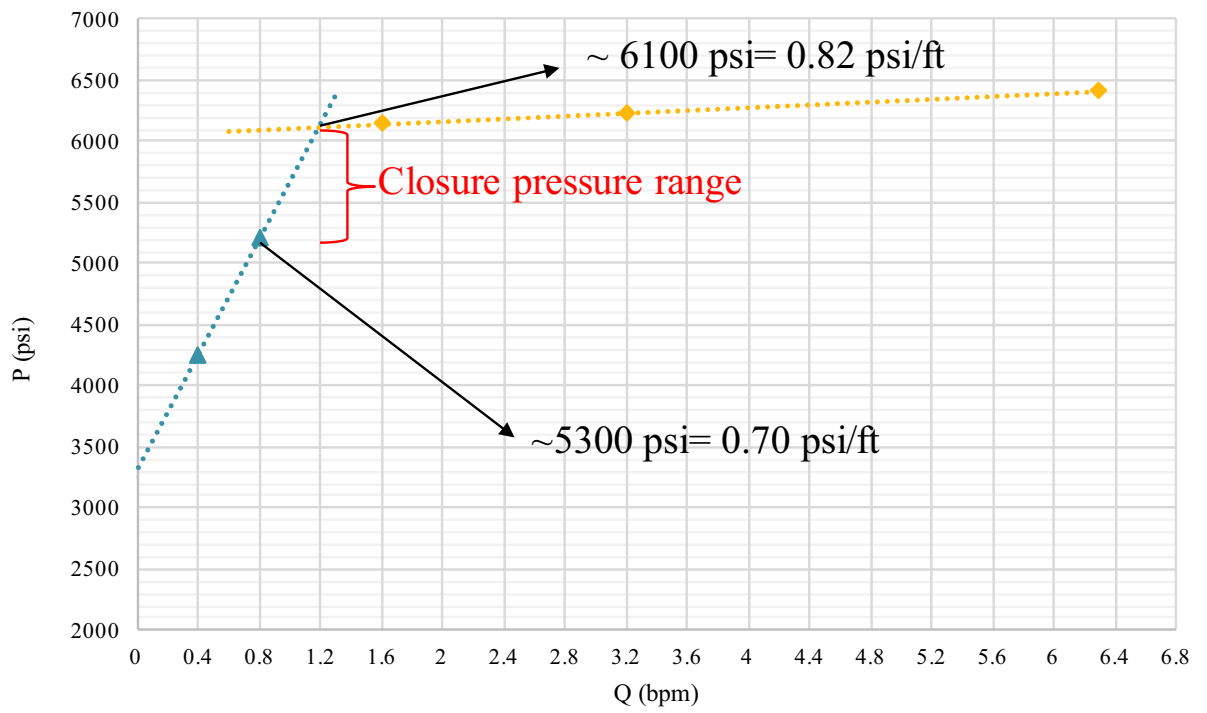

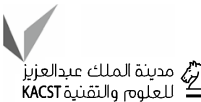
Springer 
Acknowledgements Funding for this work was provided by the U.S. DOE under Grant DE-EE0007080 "Enhanced Geothermal System Concept Testing and Development at the Milford City, Utah FORGE Site." We thank the many stakeholders who are supporting this project, including Smithfield, Utah School and Institutional Trust Lands Administration, and Beaver County as well as the Utah Governor's Office of Energy Development.

Open Access This article is distributed under the terms of the Creative Commons Attribution 4.0 International License (http://creativeco mmons.org/licenses/by/4.0/), which permits unrestricted use, distribution, and reproduction in any medium, provided you give appropriate credit to the original author(s) and the source, provide a link to the Creative Commons license, and indicate if changes were made.

\section{References}

Barree RD, Barree VL, Craig D (2009) Holistic fracture diagnostics: consistent interpretation of prefrac injection tests using multiple analysis methods. SPE Prod Oper 24(03):396-406

Barree RD, Harris HG, Towler BF, Ramurthy M (2013) Effects of high pressure-dependent leakoff (PDL) and high process-zone stress (PZS) on stimulation treatments and production. Paper presented at the SPE unconventional resources conference and exhibitionAsia Pacific

Barree RD, Miskimins J, Gilbert J (2015) Diagnostic fracture injection tests: common mistakes, misfires, and misdiagnoses. SPE Prod Oper 30(02):84-98

Bourdet D, Ayoub J, Pirard Y (1989) Use of pressure derivative in well test interpretation. SPE Form Eval 4(02):293-302

Brown E, Hoek E (1978) Trends in relationships between measured in situ stresses and depth. Paper presented at the international journal of rock mechanics and mining sciences and geomechanics abstracts

Cornet F, Bérard T (2003) A case example of integrated stress profile evaluation. Paper presented at the 3rd international symposium on rock stress

Couzens-Schultz BA, Chan AW (2010) Stress determination in active thrust belts: an alternative leak-off pressure interpretation. J Struct Geol 32(8):1061-1069

Evans KF (2005) Permeability creation and damage due to massive fluid injections into granite at $3.5 \mathrm{~km}$ at Soultz: 2. Critical stress and fracture strength. J Geophys Res Solid Earth 110(B4):1-19

Howard GC, Fast C (1957) Optimum fluid characteristics for fracture extension. Paper presented at the drilling and production practice

Ito T, Hayashi K (2003) Role of stress-controlled flow pathways in HDR geothermal reservoirs. Pure appl Geophys 160(5-6):1103-1124

Liu G, Ehlig-Economides C (2016) Interpretation methodology for fracture calibration test before-closure analysis of normal and abnormal leakoff mechanisms. Paper presented at the SPE hydraulic fracturing technology conference

Marongiu-Porcu M, Ehlig-Economides CA, Economides MJ (2011) Global model for fracture falloff analysis. Paper presented at the North American unconventional gas conference and exhibition
McClure MW, Jung H, Cramer DD, Sharma MM (2016) The fracturecompliance method for picking closure pressure from diagnostic fracture-injection tests. SPE J 21(4):1-321

Meller C, Kohl T, Gaucher E, Genter A (2012) Approach for determination of the failure probability of fractures at the Soultz-SousForêts EGS project. Paper presented at the 37th workshop on geothermal reservoir engineering

Morris A, Ferrill DA, Henderson DB (1996) Slip-tendency analysis and fault reactivation. Geology 24(3):275-278

Nadimi S (2015) State-based peridynamics simulation of hydraulic fracture phenomenon in geological media. The University of Utah, Salt Lake City

Nadimi S, Miscovic I, McLennan J (2016) A 3D peridynamic simulation of hydraulic fracture process in a heterogeneous medium. $\mathrm{J}$ Pet Sci Eng 145:444-452

Nadimi S, Forbes B, Finnila A, Podgorney R, Moore J, McLennan J (2018) Hydraulic fracture/shear stimulation in an EGS reservoir: Utah FORGE Program. ARMA2018

Nolte KG (1997) Background for after-closure analysis of fracture calibration tests. SPE-39407-MS. Society of Petroleum Engineers

Nolte KG, Smith MB (1981) Interpretation of fracturing pressures. J Pet Technol 33(09):1,767-761,775

Pine R, Batchelor A (1984) Downward migration of shearing in jointed rock during hydraulic injections. Paper presented at the international journal of rock mechanics and mining sciences and geomechanics abstracts

Poe B, Economides M, Nolte K (2000) Post-treatment evaluation and fractured well performance. In: Economides ME, Nolte KG (eds) Reservoir stimulation. Wiley, Hoboken

Ramurthy M, Marjerisson DM, Daves SB (2002) Diagnostic fracture injection test in coals to determine pore pressure and permeability. Paper presented at the SPE gas technology symposium

Valley B, Evans KF (2007) Stress state at Soultz-sous-Forêts to $5 \mathrm{~km}$ depth from wellbore failure and hydraulic observations. Paper presented at the proceedings, 32nd workshop on geothermal reservoir engineering

Xie L, Min K-B (2016) Initiation and propagation of fracture shearing during hydraulic stimulation in enhanced geothermal system. Geothermics 59:107-120

Xie L, Min KB, Song Y (2015) Observations of hydraulic stimulations in seven enhanced geothermal system projects. Renewable Energy 79:56-65

Zoback MD (2010) Reservoir geomechanics. Cambridge University Press, Cambridge

Zoback MD, Healy JH (1992) In situ stress measurements to $3.5 \mathrm{~km}$ depth in the Cajon Pass scientific research borehole: implications for the mechanics of crustal faulting. J Geophys Res Solid Earth 97(B4):5039-5057

Zoback M, Barton C, Brudy M, Castillo D, Finkbeiner T, Grollimund B, Wiprut D (2003) Determination of stress orientation and magnitude in deep wells. Int J Rock Mech Min Sci 40(7-8):1049-1076

Publisher's Note Springer Nature remains neutral with regard to jurisdictional claims in published maps and institutional affiliations. 